\title{
Seeds of change: reversing the erosion of traditional agroecological knowledge through a citizen science school program in Catalonia, Spain
}

Petra Benyei $^{1}$, Laura Aceituno-Mata ${ }^{2}$, Laura Calvet-Mir $^{1,3}$, Javier Tardio $^{4}$, Manuel Pardo-de-Santayana $^{5,6}, \underline{\text { David García-del-Amo }}^{1}$,

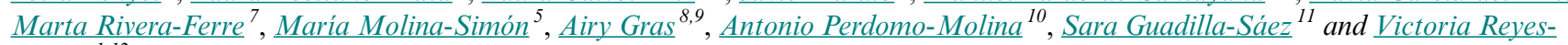
García $^{1,12}$

\begin{abstract}
Understanding valuation of and access to traditional agroecological knowledge (TAeK) in industrialized countries is key to designing initiatives that can reverse the erosion of TAeK. We explored these issues using a quasi-experimental design. We measured valuation and access to TAeK with a survey before and after an intervention based on a citizen science school program. The participants were Catalan agricultural technical students $(N=173)$, i.e., rural youth with an interest in agriculture and natural resources. We found that the study population values TAeK quite highly and accesses it relatively frequently outside the classroom. Moreover, the intervention, together with hands-on activities such as home gardening, had a positive effect on how much and how often students valued and accessed TAeK. Education programs such as the one presented here could become allies in agroecological transitions that require TAeK to be accessible and valued by future farmers.
\end{abstract}

Key Words: agroecology; citizen science; contextualized schooling; environmental education; knowledge transmission; traditional agroecological knowledge

\section{INTRODUCTION}

Traditional agroecological knowledge (TAeK) systems, understood as the set of knowledge, practices, and beliefs related to the use and management of the elements in an agroecosystem, are basic components of the world's biocultural heritage (Berkes et al. 2000, Calvet-Mir et al. 2018). Maintaining traditional knowledge systems has been an emerging priority because of their multiple social, ecological, and economic values and their potential relevance for agroecological transitions (Reyes-García 2015, Calvet-Mir et al. 2018). However, despite TAeK's dynamic and adaptive nature that allows its coexistence with other types of knowledge systems, there is a growing consensus among scientists and policy makers regarding its rapid erosion (ReyesGarcía et al. 2010, 2014, Shukla et al. 2017). Two main factors significantly contribute to traditional knowledge erosion in industrialized societies: its devaluation and its lack of transmission to younger generations (Gómez-Baggethun et al. 2010, Oteros-Rozas et al. 2013, Hernández-Morcillo et al. 2014, Iniesta-Arandia et al. 2015).

First, traditional agroecological practices in Europe have been widely abandoned, partly because of a negative valuation of TAeK systems. This valuation can be understood as the result of a set of socio-cultural, political, and economic factors that influence people's preferences and value perceptions. For instance, agriculture modernization paradigms have resulted in nonindustrial agricultural systems based on TAeK being considered outdated, inefficient, and unworthy (Naredo 2004, Gómez-Baggethun et al. 2010, Hernández-Morcillo et al. 2014). Also, the stigmatization of wild plant consumption, considered a sign of poverty in some contexts, has resulted in the erosion of wild edible plant knowledge (Cruz García 2006, Reyes-García et al. 2015). Finally, acculturation through decontextualized schooling may have also negatively affected TAeK valuation (Castagno and McKinley Jones Brayboy 2008, McCarter et al. 2014). All of these issues are framed by asymmetrical power relations that go back to colonial ideas about the underdevelopment of indigenous and local communities and that favor "expert" over "lay" knowledge (Agrawal 1995, Nadasdy 1999, Burke and Heynen 2014, Benyei et al. 2017).

Second, the lack of traditional knowledge transmission can lead to both knowledge loss and a decline in local communities' capacities to manage natural resources (Fernández-Llamazares et al. 2015, Ianni et al. 2015, Ramet et al. 2018). Traditional knowledge is accessed through a combination of different pathways that include knowledge transmission from peers (horizontal), parents (vertical), and other adults (oblique transmission; Cavalli-Sforza and Feldman 1981, Calvet-Mir et al. 2016). The relevance of these different pathways depends not only on the cultural group, but also on the age and characteristics of the learner (Reyes-García et al. 2016). In this sense, contextualized and intergenerational school activities could result in both horizontal knowledge transmission through fellow students and vertical or oblique knowledge transmission through interactions with elders. Additionaly, these activities can increase access to TAeK and help prevent the "biocultural amnesia" (Toledo and Barrera-Bassols 2008) of younger generations (McCarter and Gavin 2014, Tang and Gavin 2016).

\footnotetext{
${ }^{1}$ Institut de Ciència i Tecnologia Ambientals (ICTA) - Universitat Autònoma de Barcelona, ${ }^{2}$ Red de Semillas "Resembrando e Intercambiando", ${ }^{3}$ Internet Interdisciplinary Institute (IN3) - Universitat Oberta de Catalunya, ${ }^{4}$ Instituto Madrileño de Investigación y Desarrollo Rural, Agrario y Alimentario, ${ }^{5}$ Departamento de Biología (Botánica) - Universidad Autónoma de Madrid, ${ }^{6}$ Centro de Investigación en Biodiversidad y Cambio Global (CIBC-UAM), ${ }^{7}$ Agroecology and Food Systems Chair - University of Vic - Central University of Catalonia, ${ }^{8}$ Institut Botànic de Barcelona (IBB, CSIC - Ajuntament de Barcelona), ${ }^{9}$ Laboratori de Botànica, Facultat de Farmàcia i Ciències de l'Alimentació, Universitat de Barcelona, ${ }^{10}$ Universidad de La Laguna, ${ }_{11}$ Man and the Biosphere (MAB) Programme, Division of Ecological and Earth Sciences, UNESCO, ${ }^{12}$ Institució Catalana de Recerca i Estudis Avançats (ICREA)
} 
The general decline in TAeK has called the attention of researchers and policy makers, who have started to investigate and promote initiatives to stop the devaluation and enhance the transmission of TAeK (Tang and Gavin 2016, Benyei et al. 2020). An innovative experience in this line has been the development of citizen science school programs focused on documenting TAeK through student-led interviews, which enhance access to TAeK and contribute to counteracting social stigma and to revaluing the community's biocultural patrimony (Sieber and Strohmeier 2016, Calvet-Mir et al. 2018). Citizen science (CS) is a rapidly growing approach referring to the participation of nonprofessional scientists in scientific activities, from research design to data collection and data analysis (Wiggins and Crowston 2011, Eitzel et al. 2017). In that sense, any activity that relates to research (e.g., monitoring water quality or interviewing elders in a community) but that is done by nonprofessional researchers (e.g., lay citizens, students) can be considered CS, even if the activity is performed or framed in an educational or research institution. Normally explored in the context of "STEM" (science, technology, engineering, and math) or environmental education, CS school programs increase participants' knowledge base as well as their valuation of certain ecosystem services or natural elements (Ruiz-Mallén et al. 2016). Previously evaluated CS school programs focus on natural science issues such as biodiversity conservation or environmental monitoring, and not on biocultural issues such as TAeK conservation (Bela et al. 2016), for which it is unclear how these programs can affect issues such as students' valuation and access to TAeK. Indeed, although some research has investigated socio-cultural valuation of ecosystem services provided by TAeK-based practices (Calvet-Mir et al. 2012, Oteros-Rozas et al. 2014) and TAeK intergenerational transmission in industrialized contexts (Gómez-Baggethun et al. 2010, Calvet-Mir et al. 2016), most research in this field has focused on adults from indigenous populations who have relatively little exposure to other sources of TAeK, such as the Internet, or who have more connection to nature than do younger populations living in industrialized countries. Thus, there is a need to investigate the factors behind and the degree to which young generations in industrialized countries value and access traditional knowledge systems. More so, there is a need to evaluate the potential of CS school programs for TAeK conservation.

Here, we present results from a CS school program implemented in Catalan schools teaching agricultural technical studies. The program aimed at engaging the public in the documentation of TAeK through a "wiki"-like platform (https://www.conecte.es; Calvet-Mir et al. 2018, Benyei 2020). We explore students' (1) TAeK valuation, (2) access to TAeK, and (3) the impact of the CS program on (1) and (2). We end by discussing the implications of our results in terms of halting the erosion and promoting the maintenance of TAeK.

\section{METHODS}

We used a quasi-experimental design (i.e., an experimental design that lacks random assignment of subjects to treatment and control groups; Cook and Campbell 1979) that captured students' valuation and access to TAeK with a survey before and after an intervention consisting of exposing students to a CS school program (see Appendix 1 for details on the study context and CS program).

\section{Intervention and sampling}

Our intervention was designed based on the CONECT-e school program (see educational materials on the project's website) and had two activities. The first activity was a 50-min talk in which a researcher explained the concept of TAeK and gave some global and local examples of its importance, drivers of erosion, and potential recovery pathways. At the end of the talk, students were provided with a practical guide to document TAeK through interviews with elders. The second activity was a 50-min practical session in the school's computer room during which the students would enter the traditional knowledge they had gathered into an online wiki platform (https://www.conecte.es). Both sessions were separated by at least one month so that students would have time to interview elders. The students and their teachers had to sign a free prior informed consent sheet to be able to participate.

Because students in a class can be considered a captive population, our sampling strategy was voluntary sampling at the classroom level (i.e., sampling interested teachers that would volunteer to participate with their classes). Specifically, we invited teachers from all of the schools teaching agrarian technical studies ${ }^{[1]}$ to participate in our study via personal contacts, social media, email, and telephone. Eleven teachers from nine schools volunteered to participate with their classes in our study (15 classes in total). We then systematically assigned classes to control $(N=4)$ and treatment $(N=11)$ groups (Tuckman and Harper 2012). Group assignments were done so that both groups were relatively equivalent in terms of the number of students (i.e., some of the treatment classes had as few as four students), geographical diversity, and study programs offered. To avoid potential interference by students sharing information, we assigned classes from the same school to the same group. Some of the teachers and students were lost to follow-up (i.e., only attended the first intervention activity or were not available to respond to the postintervention survey, even though they were all approached both physically and by email). This situation left us with two treatment groups, one with students who only attended the talk $(N=59)$ and one with students who attended the talk and did the practical activity $(N=88)$, and one control group $(N=26)$ with students who answered both surveys without doing any activity (total sample size $=173$; see Fig. 1, Table 1 ).

\section{Pre- and postintervention surveys}

During the 2016-2017 academic year, we conducted the same survey at two times: once right before the first intervenion activity (but after clarifying the concept of TAeK), and once at the end of the school year, at least one month after the second intervention activity. Participants who dropped out and only did the first activity were also approached to complete the postintervention survey at the end of the school year (Table 2).

Our survey was based on a questionnaire that had three sections (Table 3; Appendix 2). The first section recorded students' valuation of TAeK using a Likert scale (Croasmun and Ostrom 2011). Based on literature exploring the values of traditional ecological knowledge (Reyes-García 2015), we proposed sentences with which students could agree or disagree on a fivepoint scale $(1=$ completely disagree, $5=$ completely agree $)$. Each sentence tried to capture the perceived value of TAeK regarding its contribution to biodiversity enhancement (V1), farm productivity (V2), identity promotion (V3), and farm sustainable 
Fig. 1. Geographical locations of the schools teaching agricultural technical studies in Catalonia, Spain.

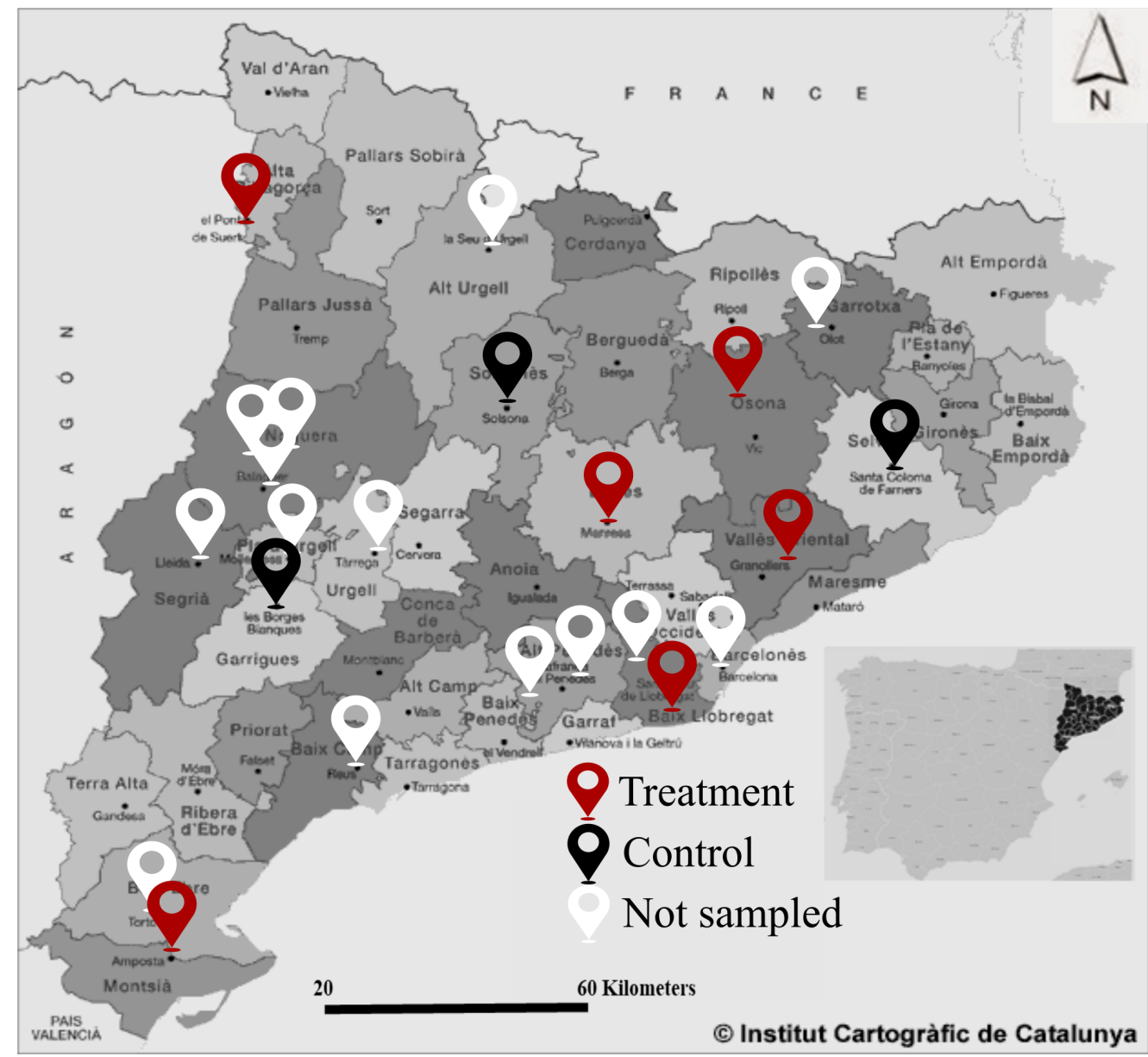

management (V4), and its validity as an updated knowledge base (V5), equally relevant as scientific knowledge (V6), and something that should be taught in schools (V7). To discourage automatic responding, some sentences were inverted (e.g., "TAeK does NOT contribute to ...”).

The second section of the questionnaire gathered data regarding the frequency with which the students talked about TAeK $(0=$ never, $1=$ rarely, $2=$ frequently). This frequency was a proxy to measure access to TAeK. We included four potential ways of accessing TAeK: elders, including parents and grandparents (A1), friends (A2), classroom (A3), and digital or physical sources (A4).

The third section of the questionnaire gathered data on the students' socio-demographic characteristics, including year of birth, sex, actual residence (town name), study program (i.e., conventional agriculture, agroecology, natural resources management, gardening, agriculture and landscape, conventional animal health, forest management), and desired work sector (i.e., organic agriculture, conventional agriculture, environmental or forestry, gardening, or other). It also captured (using dummy variables) information related to the students' rurality, measured through family ties to the primary sector $(1=$ yes $)$, current employment in a natural resources related job $(1=$ yes $)$, maintenance of a leisure home garden $(1=$ yes $)$, and stated intention to live in a rural area in the future $(1=$ yes $)$.

\section{Variables}

To construct a TAeK valuation index (TAeK_V $\mathrm{V}_{\text {sum }}$ ), we first checked the internal correlation of the seven valuation scores using Pearson correlations ("cor.test" function, R Core Team 2018). Because we found internal consistency, we added the value of the seven individual topic scores ( $2 \mathrm{TAeK}$ _Vi). The TAeK valuation index is expressed as:

$$
\begin{aligned}
& \text { TAeK_V }=\text { TAm }=\text { TAeK_V1 + TAeK_V2 + TAeK_V3 + } \\
& \text { TAeK_V4 + TAeK_V5 + TAeK_V6 + TAeK_V7 } \\
& \text { (Eqn. } 1)
\end{aligned}
$$

This index could range from 7 (a student that strongly disagreed with all topics) to 35 (a student that strongly agreed with all topics).

To build a TAeK access index (TAeK_A $\left.{ }_{\text {sum }}\right)$, we added the scores for each of the four ways of accessing TAeK ( $2 \mathrm{TAeK}$ _Ai) after checking for absence of internal association using Pearson Chisquared tests ("chisq.test" function, R Core Team 2018). The 
Table 1. Number of participants by sampled school, class level, program of study, and treatment group. $N$ $=173$.

\begin{tabular}{|c|c|c|c|c|c|}
\hline School & Class level & Program of study & Treatment group & $\begin{array}{c}\text { Number of } \\
\text { students }\end{array}$ & Subtotal \\
\hline S1 & Basic & Conventional agriculture & Control & 13 & \\
\hline \multirow[t]{2}{*}{$\mathrm{S} 2$} & High & Forest management & Control & 1 & \\
\hline & High & Agriculture and landscape & Control & 3 & \\
\hline S3 & High & Forest management & Control & 9 & 26 \\
\hline \multirow[t]{2}{*}{$\mathrm{S} 4$} & High & Forest management & Talk & 24 & \\
\hline & Basic & Natural resources management & Talk & 6 & \\
\hline \multirow[t]{2}{*}{ S5 } & Basic & Agroecology & Talk & 11 & \\
\hline & High & Agriculture and landscape & Talk & 7 & \\
\hline S6 & Basic & Agroecology & Talk & 11 & 59 \\
\hline \multirow[t]{2}{*}{ S7 } & High & Agriculture and landscape & Talk + Platform & 19 & \\
\hline & High & Conventional animal health & Talk + Platform & 23 & \\
\hline \multirow[t]{3}{*}{$\mathrm{S} 8$} & High & Forest management & Talk + Platform & 16 & \\
\hline & High & Agriculture and landscape & Talk + Platform & 16 & \\
\hline & Basic & Gardening & Talk + Platform & 11 & \\
\hline S9 & Basic & Agroecology & Talk + Platform & 3 & 88 \\
\hline
\end{tabular}

TAeK access index is expressed as:

$$
\underset{\text { TAeK_A4 }}{\text { TAeK_A }}=\underset{\text { (Eqn. } 2)}{\text { TAeK_A1 }}+\text { TAeK_A2 + TAeK_A3 + }
$$

This index could range from 0 (a student who never talked about TAeK, i.e., never accessed TAeK) to 8 (a student who frequently accessed TAeK through multiple ways).

We also recoded some of the socio-demographic variables (Table 3 ). The actual residence variable was recoded into a three-level categorical variable according to the classification of the town of residency as urban (1), intermediate (2), or rural (3) (Domínguez i Amorós et al. 2010). After examining the content and approach of the courses, the study program variable was recoded into a program theme categorical variable with three categories: alternative farming, grouping agroecology and landscape and agriculture programs (1); conventional farming, grouping conventional agriculture and conventional animal health (2); and environmental management, grouping gardening, natural resources management, and forest management (3).

\section{Data analysis}

To explore students' valuation and access to TAeK, we conducted descriptive analyses and linear mixed-effects models (LMMs) with the preintervention survey data. Specifically, we tested the association between individual covariates or fixed effects (i.e., age, sex, actual residence, program theme, desired work sector, and rurality variables) and the TAeK valuation and access indexes while controlling for interclassroom variation (random effects).

To measure the effects of the CS initiative on both students' valuation and access to TAeK, we conducted descriptive analyses of the postintervention survey data and Wilcoxon signed-rank tests and LMMs using data from both surveys. Specifically, we used nonparametric paired t-tests to compare mean scores of the indexes before and after the intervention (Pre_TAeK_V $\mathrm{V}_{\text {sum }}$ vs. Post_TAeK_V sum $_{\text {, }}$, and Pre_TAeK_A sum $_{\text {vit. }}$ vost_TAeK_A $A_{\text {sum }}$ ) and LMMs to test the effect of the treatment on the TAeK valuation and access indexes after the intervention (Post_TAeK_V ${ }_{\text {sum }}$ and Post_TAeK_A ${ }_{\text {sum }}$ ) while controlling for the baseline values (Pre_TAeK_V individual covariates, and interclassroom variation (random effects).

The LMMs were performed separately for each index. These models were built using manual stepwise backward regression, by which we began with all explanatory variables in the data set and progressively discarded those that did not significantly affect the outcome variable. Variables were only discarded if the model without them was not significantly different from the model with them (Crawley 2007). The final models were the ones that most parsimoniously explained the greatest variation in valuation and access indexes, for which variables included in each model are different. The assumptions of the final models were checked by examining the residuals (Appendix 3).

The final models were expressed by the following formulas:

$$
\begin{aligned}
& \text { Pre_TAeK_V } \mathrm{Vum}_{\text {sum }} \sim 1+\text { age }+ \text { leisure_garden }+(1 \mid \\
& \text { class) (Eqn. 3) } \\
& \text { Pre_TAeK_A } A_{\text {sum }} \sim 1+\text { program_theme }+ \text { desired_work } \\
& \text { + work_rural_nature + leisure_garden + (1 | class }) \\
& \text { (Eqn. 4) } \\
& \text { Post_TAeK_V } \mathrm{v}_{\text {sum }} \sim 1+\text { Pre_TAeK_V } \mathrm{V}_{\text {sum }}+\text { treatment } \\
& + \text { sex }+ \text { desired_work }+(1 \mid \text { class }) \text { (Eqn. 5) } \\
& \text { Post_TAeK_A } \\
& + \text { desired_residence }+(1 \mid \text { class }) \text { (Eqn. 6) }
\end{aligned}
$$

For statistical analyses, we used RStudio version 1.0.153. To perform the Wilcoxon signed-rank tests, we used the "wilcox.test" function ( $\mathrm{R}$ Core Team 2018). To conduct the mixed-effects models, we used the "lmerTest" and "lme4" packages (Bates et al. 2014). Mixed-effects models have been proven to be an effective way to account for school intervention effects in studies that include both categorical and continuous variables and that need to account for unbalanced data sets and random effects that arise during sampling, for instance, in the selection of a classroom (Wyman et al. 2010, Cunnings 2012). They are also described as being robust against violations of sphericity, homoscedasticity, and missing data (Quené and van den Bergh 2004, 2008, Kelder et al. 2005). 
Table 2. Chronogram showing the timing of the intervention activities and surveys for each school.

\begin{tabular}{|c|c|c|c|c|c|c|c|c|c|}
\hline \multirow{2}{*}{$\begin{array}{l}\text { Year of study } \\
\text { Month of study }\end{array}$} & \multicolumn{3}{|c|}{2016} & \multicolumn{6}{|c|}{2017} \\
\hline & Oct & Nov & Dec & Jan & $\mathrm{Feb}$ & Mar & Apr & May & Jun \\
\hline Preintervention survey & S5 & S9 & S7 & $\mathrm{S} 4, \mathrm{~S} 8$ & S6, S2, S3 & S1 & & & \\
\hline Activity 1: talk & S5 & S9 & S7 & $\mathrm{S} 4, \mathrm{~S} 8$ & S6 & & & & \\
\hline Activity 2: platform & & & & & & $\mathrm{S} 7, \mathrm{~S} 8, \mathrm{~S} 9$ & & & \\
\hline Postintervention survey & & & & & & & & $\begin{array}{l}\text { S1, S7, S8, } \\
\text { S9 }\end{array}$ & $\begin{array}{c}\text { S4, S5, S6, S2, } \\
\text { S3 }\end{array}$ \\
\hline
\end{tabular}

\section{RESULTS}

\section{Participant characteristics}

Participants were mainly young men between 19 and 23 years old (83\% male participants), although some were older. Two-thirds of the participants $(63.2 \%)$ were studying a high-level program and one-third (31.8\%) was studying a basic-level program. Programs were related to gardening, natural resource management, and forest management (39.9\% of participants) as well as alternative $(37.6 \%)$ and conventional farming $(22.5 \%)$.

One-quarter of the participants $(25 \%)$ wanted to work in organic farming, whereas $18.6 \%$ wanted to work in conventional farming. The remaining participants wanted to work in sectors other than agriculture, including environmental management or forestry $(32.5 \%)$ and ornamental gardening $(9.9 \%)$. Participants came from different areas in Catalonia, with $66.5 \%$ of them living in a rural or intermediate-rural town and $33.5 \%$ in an urban town. However, $73.8 \%$ of participants stated their intention to live in a rural area in the future. One-half $(50.3 \%)$ of the participants came from a family with ties to the primary sector (farming, fishing, or forestry), and a similar proportion (49.4\%) were or had been employed in a natural resources related job (e.g., in family farms or in fire prevention squads). Two-thirds of participants $(64.5 \%)$ maintained a leisure home garden.

\section{Traditional agroecological knowledge preintervention valuation and access}

Results from the preintervention survey suggest that participants highly valued TAeK before our intervention (Fig. 2). On average, most participants showed a relatively strong agreement with sentences that stated TAeK's contribution to improving farm biodiversity (mean $=4.34$ on a scale of one to five), productivity $($ mean $=3.82)$, and sustainable management $($ mean $=3.80)$. They also agreed with sentences stating that TAeK was updated (mean $=3.68$ ) and as equally relevant as scientific knowledge (mean = 3.61). The statement they most strongly agreed with was the one stating that TAeK should be taught in schools (mean = 4.53), whereas they least strongly agreed with the one stating that TAeK contributed to their identity (mean $=3.22)$.

Moreover, results from the LMMs show that the TAeK valuation index (Pre_TAeK_V ${ }_{\text {sum }}$, mean $=26.99$, SD $=3.49$; maximum possible score of 35 ) bears a positive and statistically significant association with the participant's age $(F=8.6647, P<0.01)$ and maintenance of a leisure home garden $(F=3.9348, P<0.05$; Fig. 3, Table 4; Appendix 4).

On the contrary, most participants rarely talked about TAeK with people around them, or in other words, they rarely accessed TAeK (Fig. 4). Those with whom they most often talked about TAeK were their elders $(38.7 \%$ of participants stated talking frequently about TAeK with their elders), whereas those with whom they least often talked about TAeK were their classmates (only 9.8\% of participants stated talking frequently about TAeK in the classroom). Also, only $30.6 \%$ of participants stated talking frequently about TAeK with friends and only $23.9 \%$ frequently consulted TAeK in digital or physical sources.

Fig. 2. Box plots of participants' valuation scores for the different traditional agroecological knowledge value statements before the intervention.

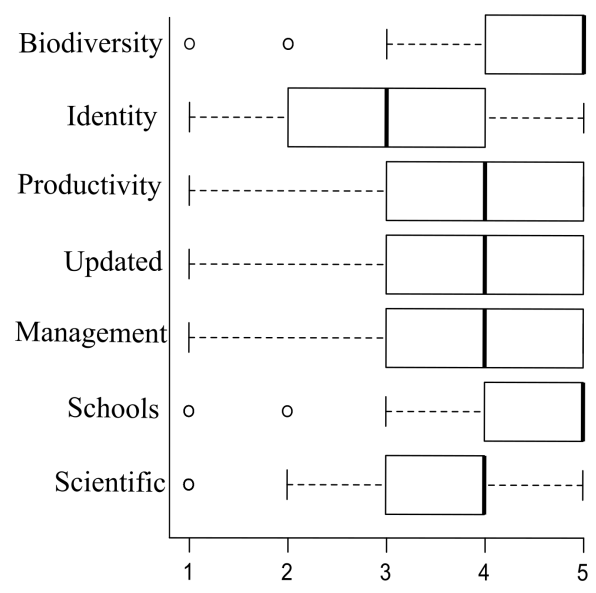

Fig. 3. Preintervention traditional agroecological knowledge (TAeK) valuation index vs. age of the participant and whether the particpant maintained a leisure home garden.

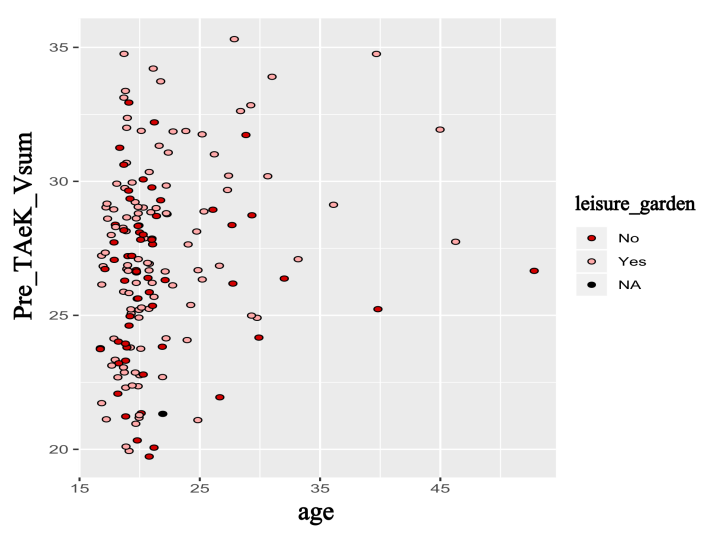


Table 3. Description of variables used in the analyses. TAeK $=$ traditional agroecological knowledge.

\begin{tabular}{|c|c|c|c|}
\hline Variable & Code & Type & Attribute \\
\hline TAeK perceived contribution to biodiversity enhancement & TAeK_V & Interval & Scale $1-5$ \\
\hline TAeK perceived contribution to farm productivity & TAeK_V & Interval & Scale $1-5$ \\
\hline TAeK perceived contribution to identity promotion & TAeK_V ${ }_{3}^{2}$ & Interval & Scale $1-5$ \\
\hline TAeK perceived contribution to farm sustainable management & TAeK_V V & Interval & Scale $1-5$ \\
\hline TAeK perceived validity as an updated knowledge base & TAeK_V ${ }_{5}^{4}$ & Interval & Scale $1-5$ \\
\hline TAeK perceived validity as equally relevant as scientific knowledge & TAeK_V V & Interval & Scale $1-5$ \\
\hline TAeK perceived validity as something that should be taught in schools & TAeK_V V & Interval & Scale $1-5$ \\
\hline TAeK valuation index & TAeK_- V & Continuous & ETAeK_V \\
\hline How frequently students talked about TAeK with elders & TAeK_Á_ & Interval & Scale $0-2$ \\
\hline How frequently students talked about TAeK with friends & TAeK_A_ & Interval & Scale $0-2$ \\
\hline How frequently students talked about TAeK in the classroom & TAeK_A_ ${ }_{3}^{2}$ & Interval & Scale $0-2$ \\
\hline How frequently students consulted TAeK in digital or physical sources & TAeK_A_ $A_{4}^{3}$ & Interval & Scale $0-2$ \\
\hline TAeK access index & TAeK_A $A_{\text {sum }}^{4}$ & Continuous & $\sum$ TAeK_A \\
\hline Age & age & Continuous & Converted year of birth \\
\hline Sex & $\operatorname{sex}$ & Dummy & $1=$ female \\
\hline Actual residence & residence & Categorical & $\begin{array}{l}1=\text { urban } \\
2=\text { intermediate } \\
3=\text { rural }\end{array}$ \\
\hline Program theme & program_theme & Categorical & $\begin{array}{l}1=\text { alternative farming } \\
2=\text { conventional farming } \\
3=\text { environmental management }\end{array}$ \\
\hline Desired work sector & desired_work & Categorical & $\begin{array}{l}1=\text { organic agriculture } \\
2=\text { conventional agriculture } \\
3=\text { environmental/forestry } \\
4=\text { gardening } \\
5=\text { other }\end{array}$ \\
\hline Family ties to the primary sector & family_primary & Dummy & $1=$ yes \\
\hline Current employment in a natural resources related job & work_rural_nature & Dummy & $1=$ yes \\
\hline Maintenance of a leisure home garden & leisure_garden & Dummy & $1=$ yes \\
\hline Intention to live in a rural area in the future & desired_residence & Dummy & $1=$ yes \\
\hline Treatment & treatment & Categorical & $\begin{array}{l}0=\text { control } \\
1=\text { only talk } \\
2=\text { talk and practical activity }\end{array}$ \\
\hline
\end{tabular}

Fig. 4. Preintervention frequency of access to traditional agroecological knowledge (TAeK) for the different access pathways.

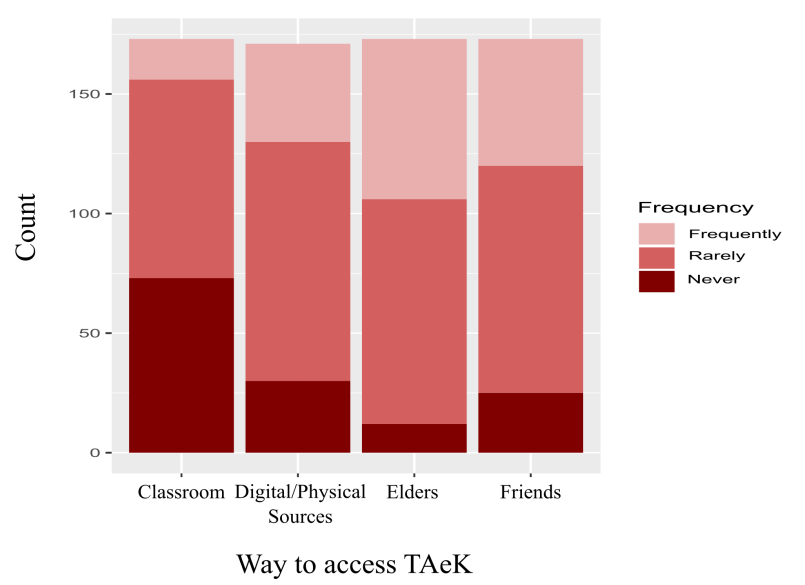

Results from the LMMs show that the TAeK access index (Pre_TAeK_A ${ }_{\text {sum }}$, mean $=4.21, \mathrm{SD}=1.83$; maximum possible score of 8$)$ is associated with the participants' program theme $(F$
$=12.0204, P<0.001)$, desired work sector $(F=2.9547, P<0.05)$, employment in a natural resources related job $(F=9.3896, P<$ $0.01)$, and maintenance of a leisure home garden $(F=13.6958, P$ $<0.001$; Fig. 5, Table 5; Appendix 4). Indeed, participants studying conventional farming and environmental management programs accessed TAeK significantly less often than participants in alternative farming programs. Also, participants who wanted to work in the conventional agriculture, environmental or forestry, gardening, and other sectors accessed TAeK significantly less often than those who wanted to work in the organic agriculture sector. Finally, participants employed in a natural resources related job or maintaining a leisure home garden accessed TAeK significantly more often than did their peers.

\section{Intervention effects on traditional agroecological knowledge valuation and access}

The mean TAeK valuation index score was not significantly higher after the intervention (Post_TAeK_V ${ }_{\text {sum }}$, mean $=26.86$, $\mathrm{SD}=3.56, P=0.5516$; Fig. 6$)$. However, there seems to be some variation in TAeK valuation when looking at specific questions, particularly TAeK's perceived contribution to identity promotion (with an increase in mean score from 3.22 to 3.31 on a scale of 15), TAeK's perceived validity as an updated knowledge base (from 3.68 to 3.71 ), and TAeK's perceived validity as equally relevant as scientific knowledge (from 3.61 to 3.76 ). 
Table 4. Best fitting model for the preintervention traditional agroecological knowledge valuation index (Pre_TAeK_V $\mathrm{V}_{\text {sum }}$ ). The most parsimonious linear mixed model was fit using restricted maximum likelihood (REML) methods. The $t$-tests use Satterthwaite approximations to degrees of freedom. Model formula $=$ Pre_TAeK_V ${ }_{\text {sum }} \sim 1+$ age + leisure_garden $+(1 \mid$ class $)$. REML criterion at convergence $=899.4$. Number of observations $=171$, groups: class, 15 .

\begin{tabular}{lccccc}
\hline \hline Fixed effect & Estimate & Standard error & $\begin{array}{c}\text { Degrees of } \\
\text { freedom }\end{array}$ & $t$ & $P$ \\
\hline Intercept & 23.17114 & 1.10926 & 168 & 20.89 & $2 \mathrm{e}-16$ \\
age & 0.14263 & 0.04723 & 168 & 3.02 & 0.00292 \\
leisure_garden_yes & 1.14675 & 0.53340 & 168 & 2.15 & 0.03299 \\
\hline
\end{tabular}

Fig. 5. Box plots of the distribution of the preintervention traditional agroecological knowledge (TAeK) access index for variables that were significantly associated with it.
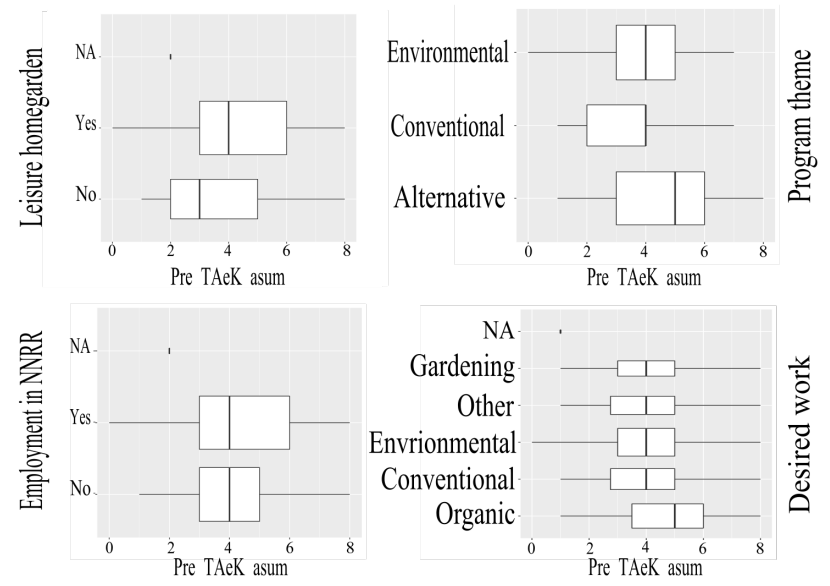

Fig. 6. Frequency distributions of the preintervention (A) and postintervention (B) traditional agroecological knowledge (TAeK) valuation index.

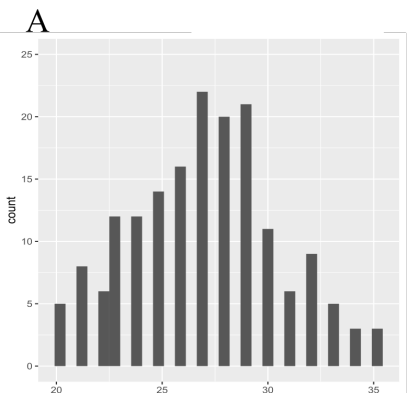

Pre_TAeK_Vsum

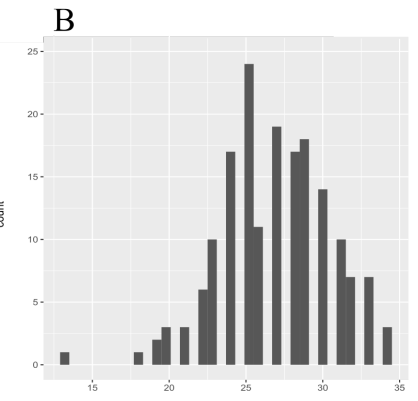

Post_TAeK_Vsum
Results from the LMMs suggest that these variations in TAeK valuation might be associated with our intervention $(F=2.2583$, $P=0.15463$ ) but also with other factors. Controlling for participants' TAeK valuation before the intervention, participation in the first intervention activity (the talk, T1) had a significant direct and positive effect on participants' valuation of
TAeK. Participation in both intervention activities (talk and practical activity, T2) was also directly and positively associated with participants' TAeK valuation, although the association was not statistically significant. Participants' gender $(F=5.4467, P<$ $0.05)$ and desired work sector $(F=3.4442, P<0.05)$ were also associated with TAeK valuation after the intervention: women valued TAeK significantly less than did men, as did participants willing to work in the conventional agriculture, environmental or forestry, and other sectors when compared to those willing to work in the organic agriculture sector (Fig. 7, Table 6; Appendix 4).

Fig. 7. Postintervention traditional agroecological knowledge (TAeK) valuation index vs. preintervention TAeK valuation index by treatment. Data points falling above the diagonal line correspond to participants that valued TAeK higher after than before the intervention.

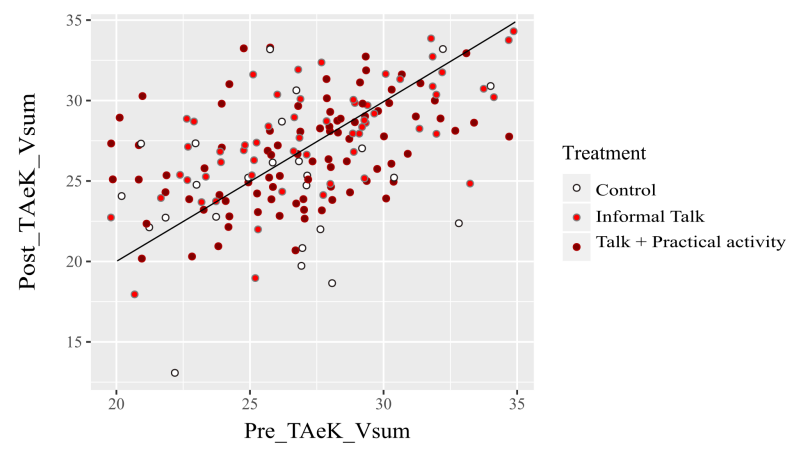

The effect of the intervention was more evident when looking at access to TAeK. Indeed, although results were not statistically significant, participants seem to have accessed TAeK more often after than before the intervention (Post_TAeK_A sum $_{\text {, }}$ mean = $4.39, \mathrm{SD}=1.63, P=0.1701$; Fig. 8 ). Specifically, compared with the answers before the intervention, participants talked more frequently about TAeK with friends and in the classroom, and also consulted TAeK more frequently in digital and physical sources after the intervention. In fact, the proportion of students that never talked about TAeK with friends or in the classroom went down $6.4 \%$ and $19.1 \%$, respectively. 
Table 5. Best fitting model for the preintervention traditional agroecological knowledge access index (Pre_TAeK_A parsimonious linear mixed model was fit using restricted maximum likelihood (REML) methods. The $t$-tests use Satterthwaite approximations to degrees of freedom. Model formula $=$ Pre_TAeK_A + leisure_garden $+(1 \mid$ class $)$. REML criterion at convergence $=638.2$. Number of observations $=171$, groups: class, 15 .

\begin{tabular}{|c|c|c|c|c|c|}
\hline Fixed effect & Estimate & Standard error & $\begin{array}{c}\text { Degrees of } \\
\text { freedom }\end{array}$ & $t$ & $P$ \\
\hline Intercept & 4.6797 & 0.3650 & 162 & 12.819 & $<2 \mathrm{e}-16$ \\
\hline program_theme $=$ conventional farming & -1.8879 & 0.3887 & 162 & -4.857 & $2.79 \mathrm{e}-06$ \\
\hline program_theme $=$ environmental management & -0.7877 & 0.3216 & 162 & -2.449 & 0.015397 \\
\hline desired_work = conventional agriculture & -0.7932 & 0.3916 & 162 & -2.025 & 0.044475 \\
\hline desired_work $=$ environmental or forestry & -0.9946 & 0.3658 & 162 & -2.719 & 0.007264 \\
\hline desired_work $=$ other & -0.9092 & 0.4121 & 162 & -2.206 & 0.028776 \\
\hline desired_work $=$ gardening & -1.2757 & 0.4936 & 162 & -2.584 & 0.010639 \\
\hline work_rural_nature $=$ yes & 0.7757 & 0.2532 & 162 & 3.064 & 0.002557 \\
\hline leisure_garden $=$ yes & 0.9894 & 0.2673 & 162 & 3.701 & 0.000294 \\
\hline
\end{tabular}

Fig. 8. Frequency distributions of the preintervention (A) and postintervention (B) traditional agroecological knowledge (TAeK) access index.
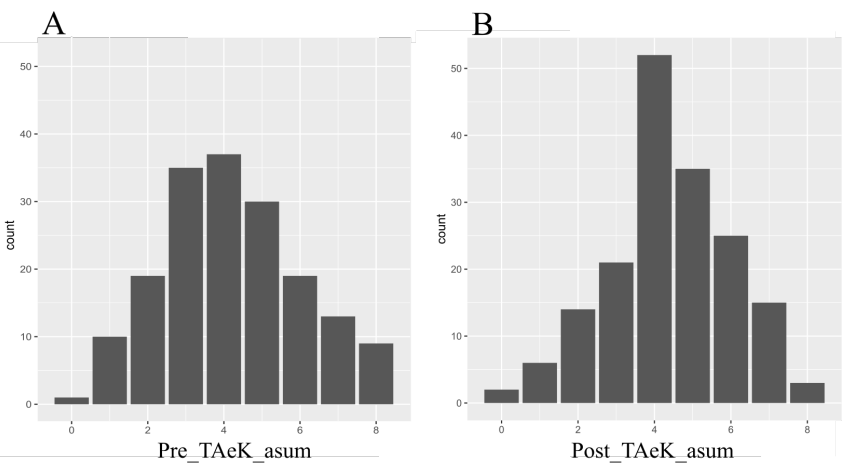

The LMMs showed that, controlling for the preintervention answers, both treatments had a significant direct and positive effect on the postintervention TAeK access index $(F=4.2503, P$ $<0.05)$. In other words, attending the talk and using the CONECT-e platform significantly increased the frequency with which participants talked about TAeK. Access to TAeK after the intervention was also positively associated with a participant's desire to live in a rural area in the future $(F=8.2162, P<0.01$; Fig. 9, Table 7; Appendix 4).

\section{DISCUSSION}

Our results contribute to understanding valuation and access to TAeK among young rural populations of industrialized countries. Moreover, they also shed light on the potential of CS school programs in terms of increasing valuation and access to TAeK. Before discussing these results, we address some of the caveats that might have potentially affected them.

\section{Caveats}

The first caveat of our study relates to potential sampling biases. Schools selected for the study mainly focused on agricultural or environmental education, and most of them were located in rural areas where TAeK-holders live. Although this sampling strategy makes sense in the context of our study, it also reduces the external validity of the results because the study participants do not represent the average youth in industrialized countries, but are a subsample with previous interest in agricultural and environmental topics and that have easy access to traditional knowledge holders. Moreover, our study faces self-selection biases for two reasons. First, teachers voluntarily enrolled their students in the activity, which might result in a self-selection of students with previously interested teachers that could, in turn, be influencing their students. Second, students were able to abandon the study by not answering the postintervention survey (in fact $19.5 \%$ did so), which might have biased our sample toward students who are more willing to participate in our activities.

Fig. 9. Postintervention traditional agroecological knowledge (TAeK) access index vs. preintervention TAeK access index by treatment. Data points falling above the diagonal line correspond to participants that accessed TAeK more frequently after than before the intervention.

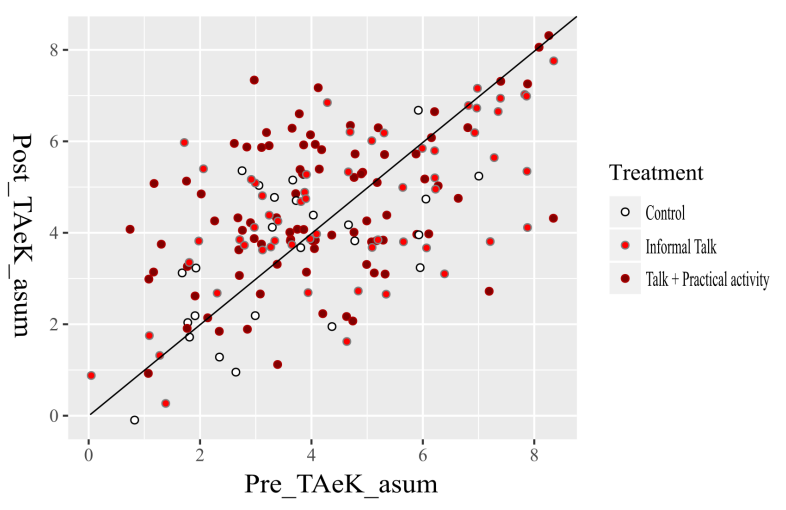

Second, the survey design might have affected participants' responses. On the one hand, the use of a five-point Likert scale limited the valuation score's range. This meant that if a participant valued TAeK very highly before the intervention (5), he/she would not be able to increase this value after the intervention. In this case, the null (or negative) valuation change probably relates more to the measurement instrument than to a real valuation change. 
Table 6. Best fitting model for the postintervention traditional agroecological knowledge valuation index (Post_TAeK_V parsimonious linear mixed model was fit using restricted maximum likelihood (REML) methods. The $t$-tests use Satterthwaite approximations to degrees of freedom. Model formula $=$ Post_TAeK_V ${ }_{\text {sum }} \sim 1+$ Pre_TAeK_V $+(1 \mid$ class $)$. REML criterion at convergence $=843.6$. Number of observations $=172$, groups: class, 15.

\begin{tabular}{|c|c|c|c|c|c|}
\hline Fixed effect & Estimate & Standard error & Degrees of freedom & $t$ & $P$ \\
\hline Intercept & 15.02391 & 1.88501 & 147.57539 & 7.970 & $3.97 \mathrm{e}-13$ \\
\hline Pre_TAeK_V & 0.44823 & 0.06416 & 157.32076 & 6.987 & $7.51 \mathrm{e}-11$ \\
\hline treatment $=$ talk & 1.87197 & 0.87023 & 14.53101 & 2.151 & 0.04873 \\
\hline treatment $=$ talk + practical & 1.33078 & 0.79913 & 11.38433 & 1.665 & 0.12311 \\
\hline gender $=$ female & -1.40591 & 0.61017 & 162.66098 & -2.304 & 0.02248 \\
\hline desired_work = conventional agriculture & -2.32367 & 0.73306 & 148.06599 & -3.170 & 0.00185 \\
\hline desired_work $=$ environmental or forestry & -1.74521 & 0.63195 & 105.78336 & -2.762 & 0.00678 \\
\hline desired_work $=$ other & -1.70314 & 0.74548 & 162.04090 & -2.285 & 0.02363 \\
\hline desired_work = gardening & -0.65308 & 0.86116 & 142.09345 & -0.758 & 0.44948 \\
\hline
\end{tabular}

On the other hand, the fact that the surveys were done with the teacher and researcher in the classroom could lead to social desirability response bias (van de Mortel 2008), meaning that the students might have reported high valuation and access to TAeK just because they thought they were expected to do so.

The third caveat relates to the selection of variables. We focused on two of the variables (valuation and access) that the literature has highlighted as key to the maintenance of TAeK (GómezBaggethun et al. 2010, Hernández-Morcillo et al. 2014). However, there could be unmeasured confounding variables for which we cannot assume that students who value highly and talk a lot about TAeK would be more likely to use TAeK in the future.

A final caveat relates to the lack of more baseline and longitudinal measures. Although the access to TAeK could be indicative of TAeK transmission in the sense that there is a chance for transmission if a person talks frequently about TAeK, we cannot demonstrate that the transmission was effective in the long term unless we measure the baseline knowledge and whether students actually retained the information after some time.

\section{To value or not to value}

Findings from this work point out two main issues in relation to the devaluation of TAeK. First, our results point out that students who enroll in agricultural technical studies in Catalonia value TAeK quite highly. In fact, they strongly agree with statements related to the importance of including TAeK in school curricula and to the equal value of TAeK and scientific knowledge. Although these results may only be representative of our sample, they show a tendency toward overcoming the previously reported devaluation of traditional knowledge systems in favor of "expert" knowledge systems (Agrawal 1995, Nadasdy 1999, Naredo 2004, Gómez-Baggethun et al. 2010, Burke and Heynen 2014, Hernández-Morcillo et al. 2014). Indeed, our results might be indicative of a revalorization of TAeK by young generations of future alternative farmers, a trend that could break with the abandonment of TAeK reported in Spain, and in Europe in general (Naredo 2004, Hernández-Morcillo et al. 2014).

Second, our results highlight that the most important factors affecting the valuation of TAeK among agricultural technical students in Catalonia are age, maintenance of a leisure home garden, and willingness to work in the organic farming sector. Older students, students who spend leisure time working in a home garden, and students who would like to work in the organic sector in the future value TAeK more than their peers do. Considering that TAeK is experience based, learner centered, and acquired through contextualized interaction with community members (Lancy 1996, Hunn 2002, Reyes-García et al. 2010, McCarter and Gavin 2011), it seems logical that older students, who have been able to spend more time with elders and in nature, and who are willing to do so in the future, also value TAeK more. Most importantly, our results could be understood as a call for including hands-on gardening activities in the school curricula of younger students to promote the revalorization of TAeK.

\section{Accessing traditional agroecological knowledge}

TAeK was most frequently accessed by talking with elders and was rarely accessed by talking about TAeK in class. Talking about TAeK with friends and consulting digital sources occurred more frequently than talking about TAeK in class but was still not very frequent. Assuming that talking about TAeK can mean opening the possibility to TAeK transmission, and considering the different transmission pathways described in the introduction, our results suggest that in our case study, oblique and vertical transmission pathways (talking with elders) were more frequent than horizontal pathways (talking in class and with friends). Moreover, the overall use of these pathways was positively associated with studying an alternative farming program, working in a natural resources related job, willingness to work in the organic farming sector, willingness to live in a rural area in the future, and maintenance of a leisure home garden. These results are not surprising; previous research shows that the main pockets of TAeK in Spain are held by elderly rural populations and that schools rarely include TAeK in their curricula (Reyes-García et al. 2014, Ramet et al. 2018), for which students need to access TAeK through pathways outside the classroom. The finding, however, has some potential implications for TAeK maintenance.

First, when analyzing the use of different transmission pathways, several authors have highlighted the importance of "scaffolding", or learning from a more knowledgeable person (normally an elder), particularly for the acquisition of complex skills (Reiser and Tabak 2014, Reyes-García et al. 2016). This concept applies to the transmission of TAeK, which requires the intervention of a more knowledgeable person who explains and guides the learner through the complexity of TAeK-based practices. Thus, in the context of traditional knowledge systems, the literature reports 
Table 7. Best fitting model for the postintervention traditional agroecological knowledge access index (Post_TAeK_A sum $_{\text {_t }}$. The most parsimonious linear mixed model was fit using restricted maximum likelihood (REML) methods. The $t$-tests use Satterthwaite approximations to degrees of freedom. Model formula $=$ Post_TAeK_A sum $_{-} \sim 1+$ Pre_TAeK_A Treatment + desired_residence $+(1 \mid$ class $)$. REML criterion at convergence $=583.6$. Number of observations $=172$, groups: class, 15 .

\begin{tabular}{|c|c|c|c|c|c|}
\hline Fixed effect & Estimate & Standard error & Degrees of freedom & $t$ & $P$ \\
\hline Intercept & 1.39638 & 0.36485 & 167 & 3.827 & 0.000183 \\
\hline Pre_TAeK_A & 0.43624 & 0.05608 & 167 & 7.778 & $7.23 \mathrm{e}-13$ \\
\hline treatment $=$ talk & 0.75799 & 0.31202 & 167 & 2.429 & 0.016187 \\
\hline treatment $=$ talk + practical & 0.84278 & 0.29317 & 167 & 2.875 & 0.004571 \\
\hline desired_residence $=$ yes & 0.65787 & 0.22951 & 167 & 2.866 & 0.004687 \\
\hline
\end{tabular}

oblique and vertical transmission as key transmission pathways (see, for instance, Lozada et al. 2006). However, the literature also highlights that horizontal transmission is very relevant for TAeK maintenance because similar aged peers will be able to track changes, becoming the best source of updated information (Reyes-García et al. 2016). Thus, considering our results, more emphasis should be placed on promoting horizontal TAeK transmission to improve the TAeK-based skills of future farmers and contribute to TAeK maintenance.

Second, independently of the transmission pathway used, and to halt TAeK erosion, our results call for reinforcing those factors favoring access to TAeK. For instance, because access to TAeK was positively associated with studying, working, and spending leisure time in alternative farming, supporting these activities and facilitating hands-on experiences related to TAeK might be key to encouraging TAeK transmission, a crucial step in TAeK maintenance (Abioye et al. 2014, Llerena del Castillo and Espinet 2017, Eugenio and Aragón 2018).

\section{CONECT-e: seeds of change}

A main finding of this work is that including explanations and technology-mediated exercises related to TAeK documentation in school activities had a positive effect both on the valuation of and access to this knowledge system. Moreover, the resources needed to achieve some results are relatively modest (i.e., two 50min sessions, in our case). This result helps us unveil the potential of CS school programs as tools for TAeK conservation. Previous literature on the field of environmental education in general and $\mathrm{CS}$ in particular had reported positive effects of contextualized school programs in the valuation and acquisition of indigenous ecological knowledge (Ruiz-Mallen et al. 2009, Shukla et al. 2017). Still, to our knowledge, this is the first time a CS school program developed in an industrialized context was found to have a positive impact on the valuation of and access to TAeK. However, two issues must be highlighted in relation to the limits of this tool to halt TAeK erosion.

First, we must be careful when interpreting our results because the differences in mean valuation and access scores before and after the intervention were not statistically significant. Moreover, the effect of the CS program was lower on students' valuation than on their access to TAeK. This result could be caused by our measurement methods (see Discussion: Caveats), but it could also signal limitations of CS approaches when trying to improve TAeK valuation. Still, even if the intervention's impact was not so high, our results highlight that these types of programs encourage students to talk more about TAeK, a key aspect for its revitalization. Longitudinal studies are needed to assess whether the effect of this type of program increases over time.

Second, we must consider that the intervention had effects even without the use of the CS platform. Just attending the talk was positively associated with students' valuation and access to TAeK. This result highlights that the initial approach of the CONECTe project (using an online platform to promote TAeK sharing through intergenerational activities) might not be the only way to halt TAeK devaluation and lack of transmission among younger generations in industrialized contexts. Indeed, it is possible that simpler efforts, such as including TAeK in school curricula though informal talks, might already be a good enough tool to increase TAeK's perceived value and transmission, as has already been reported in the literature (McCarter and Gavin 2014, Tang and Gavin 2016).

\section{CONCLUSION}

This study contributes to the understanding of how to halt TAeK erosion by exploring the factors behind valuation and access to TAeK and by evaluating the effect of a CS school program on both. Four main conclusions can be drawn from this research. First, the study population, i.e., youth studying agricultural technical programs in Catalonia, values TAeK highly and talks relatively frequently about it with elders. Second, encouraging hands-on activities such as home gardening and reinforcing students' interest in alternative farming may increase students' valuation and access to TAeK. Third, relatively simple school programs can have a positive effect on how much and how often the young generations of future farmers in industrialized contexts value and access TAeK. Finally, the promotion of these types of initiatives could be critical for agroecological transitions because they require young farmers to value and access TAeK. Longitudinal studies are required to test whether and why students who engaged in a CS school program focusing on TAeK documentation actually put this knowledge to practice in their future life, which is the only way for this knowledge to be kept alive.

${ }^{[1]}$ The agrarian technical studies taught in Catalonia can be basiclevel studies (i.e., students are only required to have completed secondary high school) or high-level studies (i.e., students are required to have completed university preparatory courses) and include programs focusing on landscaping, forest management, and agricultural production, among others. 
Responses to this article can be read online at: http://www.ecologyandsociety.org/issues/responses. $\mathrm{php} / 11471$

\section{Acknowledgments:}

The authors acknowledge the efforts of all the teachers that (together with their students) participated in this study for their enthusiasm and for believing in the CONECT-e project. We also thank the CONECT-e team, including all the researchers, technical staff, and partners from the nongovernmental organization "Red de Semillas: Resembrando e intercambiando", for helping in designing, testing, and disseminating the CONECT-e platform and school program. More specifically, we thank Mònica Junyent Correas for her help with preparing and conducting the intervention activities, as well as with preparing the data set for analysis. Research leading to this study received funding from the Ministry of Economy and Competitiveness through project grant CSO2014-59704-P and contract grant BES-2015-072155 awarded to the first author. This research was also supported by projects 2017 SGR1116 from Generalitat de Catalunya (Catalan government) and PRO2017S02-VALLES from the Institut d'Estudis Catalans. Finally, we acknowledge financial support from the Spanish Ministry of Science, Innovation and Universities, through the "Maria de Maeztu" program for Units of Excellence (MDM-2015-0552).

\section{Data Availability Statement:}

The datalcode that support the findings of this study are available on request from the corresponding author. The datalcode are not publicly available due to restrictions (they contain information that could compromise the privacy of research participants).

\section{LITERATURE CITED}

Abioye, A. A., Y. A. Zaid, and H. S. Egberongbe. 2014. Documenting and disseminating agricultural indigenous knowledge for sustainable food security: the efforts of agricultural research libraries in Nigeria. Libri 64(1):75-84. https://doi. org/10.1515/libri-2014-0007

Agrawal, A. 1995. Dismantling the divide between indigenous and scientific knowledge. Development and Change 26(3):413-439. https://doi.org/10.1111/j.1467-7660.1995.tb00560.x

Bates, D., M. Maechler, B. Bolker, and S. Walker. 2014. Ime4: linear mixed-effects models using 'Eigen' and S4. R package version 1.0-6. [online] URL: https://cran.r-project.org/web/ packages/lme4/index.html

Bela, G., T. Peltola, J. C. Young, B. Balázs, I. Arpin, G. Pataki, J. Hauck, E. Kelemen, L. Kopperoinen, A. van Herzele, H. Keune, S. Hecker, M. Suskevics, H. E. Roy, P. Itkonen, M. Külvik, M. László, C. Basnou, J. Pino, and A. Bonn. 2016. Learning and the transformative potential of citizen science. Conservation Biology 30(5):990-999. https://doi.org/10.1111/cobi.12762

Benyei, P. 2020. Open granaries: preventing traditional agroecological knowledge erosion and enclosure in the era of open science. Dissertation. Universitat Autònoma de Barcelona, Barcelona, Spain.
Benyei, P., G. Arreola, and V. Reyes-García. 2020. Storing and sharing: a review of indigenous and local knowledge conservation initiatives. Ambio 49:218-230. https://doi.org/10.1007/s13280-019-01153-6

Benyei, P., N. Turreira-Garcia, M. Orta-Martínez, and M. CartróSabaté. 2017. Globalized conflicts, globalized responses. Changing manners of contestation among indigenous communities. Pages 233-250 in V. Reyes-García and A. Pyhälä, editors. Hunter-gatherers in a changing world. Springer, Cham, Switzerland. https://doi.org/10.1007/978-3-319-42271-8 13

Berkes, F., J. Colding, and C. Folke. 2000. Rediscovery of traditional ecological knowledge as adaptive management. Ecological Applications 10(5):1251-1262. https://doi.org/10.1890/1051-0761 (2000)010[1251:ROTEKA]2.0.CO;2

Burke, B. J., and N. Heynen. 2014. Transforming participatory science into socioecological praxis: valuing marginalized environmental knowledges in the face of neoliberalization of nature and science. Environment and Society: Advances in Research 5(1):7-27. https://doi.org/10.3167/ares.2014.050102

Calvet-Mir, L., P. Benyei, L. Aceituno-Mata, M. Pardo-deSantayana, D. López-García, M. Carrascosa-García, A. Perdomo-Molina, and V. Reyes-García. 2018. The contribution of traditional agroecological knowledge as a digital commons to agroecological transitions: the case of the CONECT-e platform. Sustainability 10(9):3214. https://doi.org/10.3390/su10093214

Calvet-Mir, L., E. Gómez-Baggethun, and V. Reyes-García. 2012. Beyond food production: ecosystem services provided by home gardens. A case study in Vall Fosca, Catalan Pyrenees, northeastern Spain. Ecological Economics 74:153-160. https:// doi.org/10.1016/j.ecolecon.2011.12.011

Calvet-Mir, L., C. Riu-Bosoms, M. González-Puente, I. RuizMallén, V. Reyes-García, and J. L. Molina. 2016. The transmission of home garden knowledge: safeguarding biocultural diversity and enhancing social-ecological resilience. Society and Natural Resources 29(5):556-571. https://doi. org/10.1080/08941920.2015.1094711

Castagno, A. E., and B. McKinley Jones Brayboy. 2008. Culturally responsive schooling for indigenous youth: a review of the literature. Review of Educational Research 78(4):941-993. https://doi.org/10.3102/0034654308323036

Cavalli-Sforza, L. L., and M. W. Feldman. 1981. Cultural transmission and evolution: a quantitative approach. Princeton University Press, Princeton, New Jersey, USA.

Cook, T. D., and D. T. Campbell. 1979. Quasi-experimentation: design \& analysis issues for field settings. Houghton Mifflin, Boston, Massachusetts, USA.

Crawley, M. J. 2007. The R book. Wiley, Chichester, UK.

Croasmun, J. T., and L. Ostrom. 2011. Using Likert-type scales in the social sciences. Journal of Adult Education 40(1):19-22.

Cruz García, G. S. 2006. The mother - child nexus. Knowledge and valuation of wild food plants in Wayanad, Western Ghats, India. Journal of Ethnobiology and Ethnomedicine 2:39. https:// doi.org/10.1186/1746-4269-2-39 
Cunnings, I. 2012. An overview of mixed-effects statistical models for second language researchers. Second Language Research 28 (3):369-382. https://doi.org/10.1177/0267658312443651

Domínguez i Amorós, M., N. Monllor i Rico, and M. Simó i Solsona. 2010. Món rural i joves: realitat juvenil i polítiques de joventut als municipis rurals de Catalunya. Barcelona Generalitat de Catalunya, Secretaria de Joventut, Barcelona, Spain. [online] URL: http://ejoventut.gencat.cat/permalink/41cb4ee9-2a0a-11e4$\underline{\text { bcfe-005056924a59 }}$

Eitzel, M. V., J. L. Cappadonna, C. Santos-Lang, R. E. Duerr, A. Virapongse, S. E. West, C. C. M. Kyba, A. Bowser, C. B. Cooper, A. Sforzi, A. N. Metcalfe, E. S. Harris, M. Thiel, M. Haklay, L. Ponciano, J. Roche, L. Ceccaroni, F. M. Shilling, D. Dörler, F. Heigl, T. Kiessling, B. Y. Davis, and Q. Jiang. 2017. Citizen science terminology matters: exploring key terms. Citizen Science: Theory and Practice 2(1):1. http://doi.org/10.5334/cstp.96

Eugenio, M., and L. Aragón. 2018. Experiencias educativas en relación a la agroecología en la educación superior española contemporánea: presentación de la red universidades cultivadas. Agroecología 11(1):31-39. [online] URL: https://revistas.um.es/ agroecologia/article/view/329561

Fernández-Llamazares, Á., I. Díaz-Reviriego, A. C. Luz, M. Cabeza, A. Pyhälä, and V. Reyes-García. 2015. Rapid ecosystem change challenges the adaptive capacity of local environmental knowledge. Global Environmental Change 31:272-284. https://doi. org/10.1016/j.gloenvcha.2015.02.001

Gómez-Baggethun, E., S. Mingorría, V. Reyes-García, L. Calvet, and C. Montes. 2010. Traditional ecological knowledge trends in the transition to a market economy: empirical study in the Doñana Natural Areas. Conservation Biology 24(3):721-729. https://doi.org/10.1111/j.1523-1739.2009.01401.x

Hernández-Morcillo, M., J. Hoberg, E. Oteros-Rozas, T. Plieninger, E. Gómez-Baggethun, and V. Reyes-García. 2014. Traditional ecological knowledge in Europe: status quo and insights for the environmental policy agenda. Environment: Science and Policy for Sustainable Development 56(1):3-17. https:// doi.org/10.1080/00139157.2014.861673

Hunn, E. S. 2002. Evidence for the precocious acquisition of plant knowledge by Zapotec children. Pages 604-613 in J. R. Stepp, F. S. Wyndham, and R. K. Zarger, editors. Ethnobiology and biocultural diversity: proceedings of the seventh international congress of ethnobiology. International Society of Ethnobiology, Athens, Georgia, USA.

Ianni, E., D. Geneletti, and M. Ciolli. 2015. Revitalizing traditional ecological knowledge: a study in an alpine rural community. Environmental Management 56:144-156. https://doi. org/10.1007/s00267-015-0479-Z

Iniesta-Arandia, I., D. García del Amo, A. P. García-Nieto, C. Piñeiro, C. Montes, and B. Martín-López. 2015. Factors influencing local ecological knowledge maintenance in Mediterranean watersheds: insights for environmental policies. Ambio 44:285-296. https://doi.org/10.1007/s13280-014-0556-1

Kelder, S., D. M. Hoelscher, C. S. Barroso, J. L. Walker, P. Cribb, and S. Hu. 2005. The CATCH Kids Club: a pilot after-school study for improving elementary students' nutrition and physical activity. Public Health Nutrition 8(2):133-140. https://doi. org/10.1079/PHN2004678

Lancy, D. F. 1996. Playing on the mother-ground: cultural routines for children's development. Guilford Press, New York, New York, USA.

Llerena del Castillo, G., and M. Espinet. 2017. Agroecología escolar. Pollen Edicions, Barcelona, Spain.

Lozada, M., A. Ladio, and M. Weigandt. 2006. Cultural transmission of ethnobotanical knowledge in a rural community of northwestern Patagonia, Argentina. Economic Botany 60:374-385. https://doi.org/10.1663/0013-0001(2006)60[374:CTOEKI] 2.0.CO:2

McCarter, J., and M. C. Gavin. 2011. Perceptions of the value of traditional ecological knowledge to formal school curricula: opportunities and challenges from Malekula Island, Vanuatu. Journal of Ethnobiology and Ethnomedicine 7:38. https://doi. org/10.1186/1746-4269-7-38

McCarter, J., and M. C. Gavin. 2014. In situ maintenance of traditional ecological knowledge on Malekula Island, Vanuatu. Society and Natural Resources 27(11):1115-1129. https://doi. org/10.1080/08941920.2014.905896

McCarter, J., M. C. Gavin, S. Baereleo, and M. Love. 2014. The challenges of maintaining indigenous ecological knowledge. Ecology and Society 19(3):39. https://doi.org/10.5751/ES-06741-190339

Nadasdy, P. 1999. The politics of TEK: power and the "integration" of knowledge. Artic Anthropology 36(1-2):1-18. [online] URL: https://www.jstor.org/stable/40316502

Naredo, J. M. 2004. La evolucioón de la agricultura en España (1940-2000). Universidad de Granada, Granada, Spain.

Oteros-Rozas, E., B. Martín-López, J. A. González, T. Plieninger, C. A. López, and C. Montes. 2014. Socio-cultural valuation of ecosystem services in a transhumance social-ecological network. Regional Environmental Change 14:1269-1289. https://doi. org/10.1007/s10113-013-0571-y

Oteros-Rozas, E., R. Ontillera-Sánchez, P. Sanosa, E. GómezBaggethun, V. Reyes-García, and J. A. González. 2013. Traditional ecological knowledge among transhumant pastoralists in Mediterranean Spain. Ecology and Society 18(3):33. https:// doi.org/10.5751/ES-05597-180333

Quené, H., and H. van den Bergh. 2004. On multi-level modeling of data from repeated measures designs: a tutorial. Speech Communication 43(1-2):103-121. https://doi.org/10.1016/j. specom.2004.02.004

Quené, H., and H. van den Bergh. 2008. Examples of mixedeffects modeling with crossed random effects and with binomial data. Journal of Memory and Language 59(4):413-425. https://doi. org/10.1016/j.jml.2008.02.002

R Core Team. 2018. R: a language and environment for statistical computing. R Foundation for Statistical Computing, Vienna, Austria.

Ramet, A., P. Benyei, M. Parada, L. Aceituno-Mata, D. Garcíadel-Amo, and V. Reyes-García. 2018. Grandparents' proximity and children's traditional medicinal plant knowledge: insights 
from two schools in intermediate-rural Spain. Journal of Ethnobiology 38(2):187-204. https://doi.org/10.2993/0278-0771-38.2.187

Reiser, B. J., and I. Tabak. 2014. Scaffolding. Pages 44-62 in R. $\mathrm{K}$. Sawyer, editor. Cambridge handbook of the learning sciences. Second Edition. Cambridge University Press, Cambridge, UK. https://doi.org/10.1017/CBO9781139519526.005

Reyes-García, V. 2015. The values of traditional ecological knowledge. Pages 283-306 in J. Martínez-Alier and R. Muradian, editors. Handbook of ecological economics. Edward Elgar, Cheltenham, UK. https://doi.org/10.4337/9781783471416.00016

Reyes-García, V., L. Aceituno-Mata, L. Calvet-Mir, T. Garnatje, E. Gómez-Baggethun, J. J. Lastra, R. Ontillera, M. Parada, M. Rigat, J. Vallè, S. Vila, and M. Pardo-de-Santayana. 2014. Resilience of traditional knowledge systems: the case of agricultural knowledge in home gardens of the Iberian Peninsula. Global Environmental Change 24:223-231. https://doi.org/10.1016/ j.gloenvcha.2013.11.022

Reyes-García, V., S. Gallois, and K. Demps. 2016. A multistage learning model for cultural transmission: evidence from three indigenous societies. Pages 47-60 in H. Terashima and B. Hewlett, editors. Social learning and innovation in contemporary huntergatherers: evolutionary and ethnographic perspectives. Springer, Tokyo, Japan. https://doi.org/10.1007/978-4-431-55997-9 4

Reyes-García, V., E. Kightley, I. Ruiz-Mallén, N. Fuentes-Peláez, K. Demps, T. Huanca, and M. R. Martínez-Rodríguez. 2010. Schooling and local environmental knowledge: Do they complement or substitute each other? International Journal of Educational Development 30(3):305-313. https://doi.org/10.1016/ j.ijedudev.2009.11.007

Reyes-García, V., G. Menendez-Baceta, L. Aceituno-Mata, R. Acosta-Naranjo, L. Calvet-Mir, P. Domínguez, T. Garnatje, E. Gómez-Baggethun, M. Molina-Bustamante, M. Molina, R. Rodríguez-Franco, G. Serrasolses, J. Vallès, and M. Pardo-deSantayana. 2015. From famine foods to delicatessen: interpreting trends in the use of wild edible plants through cultural ecosystem services. Ecological Economics 120:303-311. https://doi. org/10.1016/j.ecolecon.2015.11.003

Ruiz-Mallen, I., L. Barraza, B. Bodenhorn, and V. Reyes-García. 2009. Evaluating the impact of an environmental education programme: an empirical study in Mexico. Environmental Education Research 15(3):371-387. https://doi.org/10.1080/1350$\underline{4620902906766}$

Ruiz-Mallén, I., L. Riboli-Sasco, C. Ribrault, M. Heras, D. Laguna, and L. Perié. 2016. Citizen science: toward transformative learning. Science Communication 38(4):523-534. https://doi.org/10.1177/1075547016642241

Shukla, S., J. Barkman, and K. Patel. 2017. Weaving indigenous agricultural knowledge with formal education to enhance community food security: school competition as a pedagogical space in rural Anchetty, India. Pedagogy, Culture and Society 25 (1):87-103. https://doi.org/10.1080/14681366.2016.1225114

Sieber, A., and G. Strohmeier. 2016. Interventionsforschung im intergenerationalen Dialog. Ein partizipatives Forschungsprojekt von Universität, Schule und Region. Pages 165-178 in R. E. Lerchster and L. Krainer, editors. Interventionsforschung: Band
2: Anliegen, Potentiale und Grenzen transdisziplinärer Wissenschaft. Springer, Wiesbaden, Germany. https://doi. org/10.1007/978-3-658-12155-6 8

Tang, R., and M. C. Gavin. 2016. A classification of threats to traditional ecological knowledge and conservation responses. Conservation and Society 14(1):57-70. https://doi. org/10.4103/0972-4923.182799

Toledo, V. M., and N. Barrera-Bassols. 2008. La memoria biocultural: la importancia ecológica de las sabidurías tradicionales. Icaria, Barcelona, Spain.

Tuckman, B. W., and B. E. Harper. 2012. Conducting educational research. Rowman and Littlefield, Lanham, Maryland, USA.

van de Mortel, T. F. 2008. Faking it: social desirability response bias in self-report research. Australian Journal of Advanced Nursing 25(4):40-48. [online] URL: https://www.ajan.com.au/ archive/Vol25/Vol_25-4_vandeMortel.pdf

Wiggins, A., and K. Crowston. 2011. From conservation to crowdsourcing: a typology of citizen science. In 44th Hawaii international conference on system sciences. Institute of Electrical and Electronics Engineers, Los Alamitos, California, USA. https://doi.org/10.1109/HICSS.2011.207

Wyman, P. A., C. H. Brown, M. LoMurray, K. Schmeelk-Cone, M. Petrova, Q. Yu, E. Walsh, X. Tu, and W. Wang. 2010. An outcome evaluation of the sources of strength suicide prevention program delivered by adolescent peer leaders in high schools. American Journal of Public Health 100(9):1653-1661. https://doi. org/10.2105/AJPH.2009.190025 


\title{
Appendix 1. Study context and citizen science program
}

\author{
Study context
}

Catalonia is situated in the north-east of Spain (Figure 1 of the manuscript). Despite its population density $\left(234.3 \mathrm{inh} . / \mathrm{km}^{2}\right)$ and the importance of the services sector $(80 \%$ of Catalan GDP, IDESCAT 2017), most of its territory is still catalogued as rural or intermediate-rural based on indicators of population density and economic activity $(73 \%$ of the municipalities have less than $130 \mathrm{inh} . / \mathrm{km}^{2}$ and $48 \%$ have a strong or moderate presence of the agrarian sector, Domínguez i Amorós et al. 2010).

As in most of Europe, agricultural intensification has shaped the Catalan rural sector with severe environmental, social and demographic consequences, including nitrification of soils, loss of biodiversity, rural depopulation, and loss of TAeK (Naredo 2004; GómezBaggethun et al. 2010; Menció et al. 2011). In the spirit of this intensification and modernization, in the 1970's and 80's agricultural technical schools were opened in some Catalan rural areas. The original aim of these schools was to continue the mission of the agricultural extension schools founded in the 1950's and 60's, i.e., to promote agricultural extension systems and train future farmers in the techniques and practices of the green revolution (Minguet Pla 2009; Generalitat de Catalunya 2018). However, the increasing demand for more sustainable agricultural systems led to the introduction of organic agriculture as part of the curriculum of some of these schools, and to the opening of new schools and curricular programs that incorporate training on agroecological techniques and environmental management. Moreover, agricultural technical studies have also started to be an option in other high schools from rural and intermediate-rural areas.

Nowadays, 23 schools teach agricultural technical studies in Catalonia (7 high schools, 14 agricultural technical schools, and 2 private schools) covering the four Catalan provinces (Minguet Pla 2009; Generalitat de Catalunya 2018, Figure 1). The students (about 1300 in 2009) receive training in a specific profession after finishing the secondary school basic level. The offered study programs vary from agroecological farming and conventional farming to ornamental gardening or forest management, and last between two and four years.

The citizen science school program

CONECT-e is a citizen science initiative that was born to document, share, and protect Traditional Ecological Knowledge (TEK) as a commons and in a participatory way (Calvet-Mir et al. 2018, Reyes-García et al. 2018a). The initiative's main tool is an online wiki platform in which registered users can enter traditional knowledge related to wild or cultivated plants (www.conecte.es).

The initiative has been co-designed by researchers from seven institutions (including most of this manuscript's authors) and the Spanish seed network ("Red de Semillas: Resembrando e Intercambiando"), a non-profit, decentralized organization that brings together more than 20 regional and local seed networks from all over Spain (Red de Semillas 2015). The project's intuition is that TAeK documentation, sharing and protection could be boosted by the use of information technologies, as these technologies help to de-centralize data collection and allow protecting the knowledge in the public domain under copy-left licenses (Calvet-Mir et al. 2018, Reyes-García et al. 2018b). 
To bridge the technological gap that traditional knowledge holders might face, young volunteers were recruited through dissemination activities (e.g., articles in the news, presentations in local fairs, workshops within university volunteer programs), the idea being that these volunteers would be the link between the elder's knowledge and the digital platform. As part of this dissemination plan, a school program was also designed to recruit technologically literate students with an interest in nature and farming (i.e., agricultural technical students) that would interview their elders and enter their TAeK in the platform.

\section{Literature cited}

Calvet-Mir, L., P. Benyei, L. Aceituno-Mata, M. Pardo-de-Santayana, D. López-García, M. Carrascosa-García, A. Perdomo-Molina, and V. Reyes-García. 2018. The Contribution of Traditional Agroecological Knowledge as a Digital Commons to Agroecological Transitions: The Case of the CONCT-e Platform. Sustainability 10(9):3214.

Domínguez i Amorós, M., N. Monllor i Rico, and M. Simó i Solsona. 2010. Món rural i joves. Realitat juvenil i polítiques de joventut als municipis rurals de Catalunya. Page Estudis: 31.

Generalitat de Catalunya. 2018. Agrarian Schools Website. http://agricultura.gencat.cat/ca/ambits/formacio-innovacio/escoles-agraries/.

Gómez-Baggethun, E., S. Mingorría, V. Reyes-garcía, L. Calvet, and C. Montes. 2010. Traditional Ecological Knowledge Trends in the Transition to a Market Economy : Empirical Study in the Doñana Natural Areas. Conservation Biology 24(3):721-729.

Menció, A., M. Boy, and J. Mas-Pla. 2011. Analysis of vulnerability factors that control nitrate occurrence in natural springs (Osona Region, NE Spain). Science of the Total Environment 409(16):3049-3058.

Minguet Pla, J. S. 2009. Estudi de l'evolució de la formació professional agrària a Catalunya. Universitat de Lleida.

Naredo, J. M. 2004. La evolución de la agricultura en España (1940-2000). Universidad de Granada, Granada, Spain.

Red de Semillas. 2015. Spain: the seed network, Resembrando e Intercambiando. Page in R. Vernooy, P. Shrestha, and B. Sthapit, editors. Community Seed Banks: Origins, Evolution and Prospects. Routledge, New York.

Reyes-García, V., L. Aceituno-Mata, P. Benyei, L. Calvet-Mir, M. Carrascosa, M. Pardo-deSantayana, and J. Tardío. 2018a. Governing landraces and associated knowledge as a commons. From theory to practice. Page in F. Girard and C. Frison, editors. The Commons, Plant Breeding and Agricultural Research. Challenges for Food Security and Agrobiodiversity. Routledge, London, UK.

Reyes-García, V., P. Benyei, and L. Calvet-Mir. 2018b. Traditional Agricultural Knowledge as a Commons. Page in J. L. Vivero Pol, T. Ferrando, O. de Schutter, and U. Mattei, editors. Routledge Handbook of Food as a Commons. Routledge, London, UK. 


\section{Appendix 2. Questionnaire}

The questionnaire used in this study can be found online here:

https://docs.google.com/forms/d/e/1FAIpQLSdOwJxwot-opyyqSKwwhWDDHa2kiErCQUTVZGg7-gJ4sNE8w/viewform?usp=sf_link 


\section{Appendix 3. R script for LMMs}

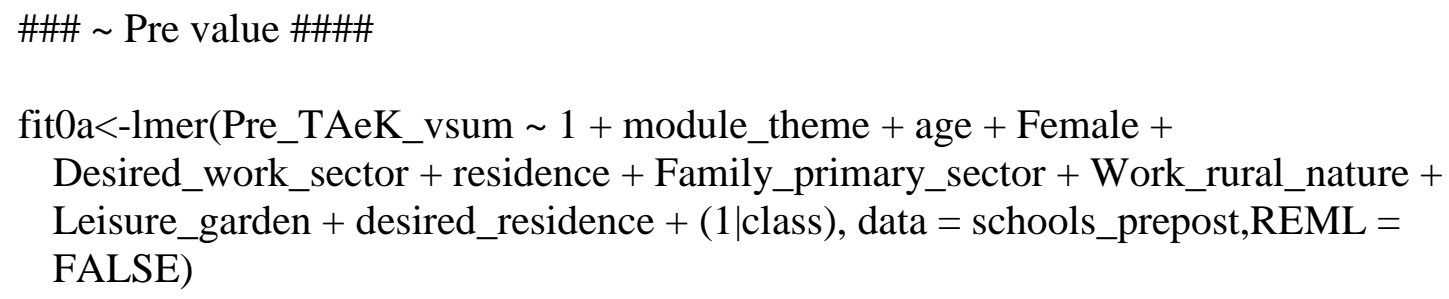


fit6<-lmer(Pre_TAeK_vsum 1 + age + Leisure_garden $+(1 \mid$ class $)$, data $=$ schools_prepost,REML $=$ FALSE)

anova(fit5,fit6)

summary(fit6)

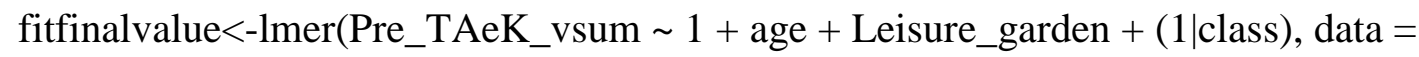
schools_prepost, REML $=$ TRUE)

summary(fitfinalvalue)

anova(fitfinalvalue)

plot(fitfinalvalue)

plot(allEffects(fitfinalvalue))

ranef(fitfinalvalue)

\#\#\# Pre transmission \#\#\#\#

fit0a $<-\operatorname{lmer}$ (Pre_TAeK_asum $\sim 1+$ module_theme + age + Female +

Desired_work_sector + residence + Family_primary_sector + Work_rural_nature + Leisure_garden + desired_residence $+(1 \mid$ class $)$, data $=$ schools_prepost,REML $=$ FALSE)

summary(fit0a)

fit1<-lmer(Pre_TAeK_asum $\sim 1+$ module_theme + age + Desired_work_sector + residence + Family_primary_sector + Work_rural_nature + Leisure_garden + desired_residence $+(1 \mid$ class $)$, data $=$ schools_prepost, REML $=$ FALSE $)$

anova(fit0a,fit1)

summary(fit1)

fit $2<-\operatorname{lmer}($ Pre_TAeK_asum $\sim 1+$ module_theme + age + Desired_work_sector + residence + Work_rural_nature + Leisure_garden + desired_residence + (1|class), data $=$ schools_prepost, REML $=$ FALSE)

anova(fit1,fit2)

summary(fit2)

fit3<-lmer(Pre_TAeK_asum $\sim 1+$ module_theme + age + Desired_work_sector + Work_rural_nature + Leisure_garden + desired_residence $+(1 \mid$ class $)$, data $=$ schools_prepost,REML = FALSE)

anova(fit2,fit3)

summary(fit3)

fit4<-lmer(Pre_TAeK_asum $~ 1+$ module_theme + age + Desired_work_sector + Work_rural_nature + Leisure_garden $+(1 \mid$ class $)$, data $=$ schools_prepost,$R E M L=$ FALSE)

anova(fit3,fit4) 
summary(fit4)

fit5<-lmer(Pre_TAeK_asum $~ 1+$ module_theme + Desired_work_sector + Work_rural_nature + Leisure_garden $+(1 \mid$ class $)$, data $=$ schools_prepost, REML $=$ FALSE)

anova(fit4,fit5)

schools_prepost_test $3<-$ schools_prepost $\%>\%$

na.exclude(age)

fit $4<-$ Imer(Pre_TAeK_asum $\sim 1+$ module_theme + age + Desired_work_sector + Work_rural_nature + Leisure_garden $+(1 \mid$ class $)$, data $=$ schools_prepost_test3,REML = FALSE)

fit5<-lmer(Pre_TAeK_asum $~ 1+$ module_theme + Desired_work_sector + Work_rural_nature + Leisure_garden $+(1 \mid$ class $)$, data $=$ schools_prepost_test3,REML = FALSE)

anova(fit4,fit5)

summary(fit5)

fitfinaltransmission<-lmer(Pre_TAeK_asum $\sim 1+$ module_theme + Desired_work_sector + Work_rural_nature + Leisure_garden $+(1 \mid$ class $)$, data $=$ schools_prepost, REML $=$ TRUE)

summary(fitfinaltransmission)

anova(fitfinaltransmission)

plot(fitfinaltransmission)

plot(allEffects(fitfinaltransmission))

ranef(fitfinaltransmission)

\#\#\#\# Value/Pre-post \#\#\#\#

fit0<-lmer(Post_TAeK_vsum $\sim 1+$ Pre_TAeK_vsum + Treatment + module_theme + age + Female + Desired_work_sector + residence + Family_primary_sector + Work_rural_nature + Leisure_garden + desired_residence $+(1 \mid$ class $)$, data $=$ schools_prepost, REML $=$ FALSE)

summary(fit0)

fit $1<-$ Imer(Post_TAeK_vsum $\sim 1+$ Pre_TAeK_vsum + Treatment + module_theme + age + Female + Desired_work_sector + residence + Family_primary_sector + Leisure_garden + desired_residence $+(1 \mid$ class $)$, data $=$ schools_prepost,$R E M L=$ FALSE)

anova(fit0,fit1)

summary(fit1) 
fit2<-lmer(Post_TAeK_vsum $\sim 1+$ Pre_TAeK_vsum + Treatment + age + Female + Desired_work_sector + residence + Family_primary_sector + Leisure_garden + desired_residence $+(1 \mid$ class $)$, data $=$ schools_prepost, REML $=$ FALSE $)$

anova(fit1,fit02)

summary(fit2)

fit3<-lmer(Post_TAeK_vsum $\sim 1+$ Pre_TAeK_vsum + Treatment + age + Female + Desired_work_sector + Family_primary_sector + Leisure_garden + desired_residence $+(1 \mid$ class $)$, data $=$ schools_prepost, REML $=$ FALSE $)$

anova(fit2,fit3)

summary(fit3)

fit4<-Imer(Post_TAeK_vsum 1 + Pre_TAeK_vsum + Treatment + age + Female + Desired_work_sector + Leisure_garden + desired_residence $+(1 \mid$ class $)$, data $=$ schools_prepost, REML = FALSE)

anova(fit3,fit4)

summary(fit4)

fit5<-lmer(Post_TAeK_vsum $\sim 1+$ Pre_TAeK_vsum + Treatment + age + Female + Desired_work_sector + desired_residence $+(1 \mid$ class $)$, data $=$ schools_prepost,REML $=$ FALSE)

anova(fit4,fit5)

summary(fit5)

fit6<-lmer(Post_TAeK_vsum $\sim 1+$ Pre_TAeK_vsum + Treatment + Female + Desired_work_sector + desired_residence $+(1 \mid$ class $)$, data $=$ schools_prepost,REML $=$ FALSE)

anova(fit5,fit6)

schools_prepost_test<-schools_prepost $\%>\%$

na.exclude(age)

fit5<-lmer(Post_TAeK_vsum $\sim 1$ + Pre_TAeK_vsum + Treatment + age + Female + Desired_work_sector + desired_residence $+(1 \mid$ class $)$, data $=$ schools_prepost_test,REML $=$ FALSE)

fit6<-lmer(Post_TAeK_vsum $\sim 1+$ Pre_TAeK_vsum + Treatment + Female + Desired_work_sector + desired_residence $+(1 \mid$ class $)$, data $=$ schools_prepost_test,REML = FALSE)

anova(fit5,fit6)

summary(fit6) 
fit7<-lmer(Post_TAeK_vsum 1 + Pre_TAeK_vsum + Treatment + Female +

Desired_work_sector $+(1 \mid$ class $)$, data $=$ schools_prepost, REML $=$ FALSE $)$

anova(fit6,fit7)

summary(fit7)

fitfinalvalue<-lmer(Post_TAeK_vsum $\sim 1+$ Pre_TAeK_vsum + Treatment + Female + Desired_work_sector $+(1 \mid$ class $)$, data $=$ schools_prepost, REML $=$ TRUE $)$

summary(fitfinalvalue)

anova(fitfinalvalue)

plot(fitfinalvalue)

plot(allEffects(fitfinalvalue))

ranef(fitfinalvalue)

\#\#\#\# Transmission/Pre-post \#\#\#\#

fit0<-lmer(Post_TAeK_asum $\sim 1+$ Pre_TAeK_asum + Treatment + module_theme + age + Female + Desired_work_sector + residence + Family_primary_sector + Work_rural_nature + Leisure_garden + desired_residence $+(1 \mid$ class $)$, data $=$ schools_prepost, REML $=$ FALSE $)$

summary(fit0)

fit1<-Imer(Post_TAeK_asum $\sim 1+$ Pre_TAeK_asum + Treatment + module_theme + age + Female + residence + Family_primary_sector + Work_rural_nature + Leisure_garden + desired_residence $+(1 \mid$ class $)$, data $=$ schools_prepost, REML $=$ FALSE $)$

anova(fit0,fit1)

summary(fit1)

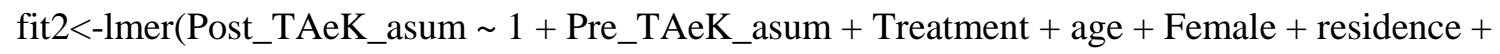
Family_primary_sector + Work_rural_nature + Leisure_garden + desired_residence + (1|class $)$, data $=$ schools_prepost, REML $=$ FALSE)

anova(fit1, fit2)

summary(fit2)

fit3<-lmer(Post_TAeK_asum 1 + Pre_TAeK_asum + Treatment + age + residence + Family_primary_sector + Work_rural_nature + Leisure_garden + desired_residence $+(1 \mid$ class $)$, data $=$ schools_prepost, REML $=$ FALSE)

anova(fit2,fit3)

summary(fit3) 
fit4<-lmer(Post_TAeK_asum $\sim 1+$ Pre_TAeK_asum + Treatment + age +

Family_primary_sector + Work_rural_nature + Leisure_garden + desired_residence + (1|class $)$, data $=$ schools_prepost, REML $=$ FALSE)

anova(fit3,fit4)

schools_prepost_test<-schools_prepost $\%>\%$

na.exclude(residence)

fit3<-lmer(Post_TAeK_asum 1 + Pre_TAeK_asum + Treatment + age + residence +

Family_primary_sector + Work_rural_nature + Leisure_garden + desired_residence $+(1 \mid$ class $)$, data $=$ schools_prepost_test, REML $=$ FALSE)

fit4<-lmer(Post_TAeK_asum 1 + Pre_TAeK_asum + Treatment + age +

Family_primary_sector + Work_rural_nature + Leisure_garden + desired_residence + (1|class), data $=$ schools_prepost_test, REML $=$ FALSE)

anova(fit3,fit4)

summary(fit4)

fit5<-lmer(Post_TAeK_asum $~ 1+$ Pre_TAeK_asum + Treatment + age +

Family_primary_sector + Work_rural_nature + desired_residence $+(1 \mid$ class $)$, data $=$

schools_prepost,REML $=$ FALSE)

anova(fit4,fit5)

summary(fit5)

fit6<-lmer(Post_TAeK_asum 1 + Pre_TAeK_asum + Treatment + age + Family_primary_sector + desired_residence $+(1 \mid$ class $)$, data $=$ schools_prepost,REML $=$ FALSE)

anova(fit5,fit6)

schools_prepost_test<-schools_prepost $\%>\%$

na.exclude(Work_rural_nature)

fit5<-lmer(Post_TAeK_asum $~ 1+$ Pre_TAeK_asum + Treatment + age +

Family_primary_sector + Work_rural_nature + desired_residence $+(1 \mid$ class $)$, data $=$

schools_prepost_test,REML $=$ FALSE)

fit6<-lmer(Post_TAeK_asum 1 + Pre_TAeK_asum + Treatment + age +

Family_primary_sector + desired_residence $+(1 \mid$ class $)$, data $=$ schools_prepost_test, REML $=$

FALSE)

anova(fit5,fit6)

summary(fit6)

fit7<-lmer(Post_TAeK_asum 1 + Pre_TAeK_asum + Treatment + age + desired_residence + $(1 \mid$ class $)$, data $=$ schools_prepost, REML $=$ FALSE $)$ 
anova(fit6,fit7)

summary(fit7)

fit8<-lmer(Post_TAeK_asum 1 + Pre_TAeK_asum + Treatment + desired_residence + $(1 \mid$ class $)$, data $=$ schools_prepost, REML $=$ FALSE $)$

anova(fit7,fit8)

schools_prepost_test<-schools_prepost $\%>\%$

na.exclude(age)

fit7<-lmer(Post_TAeK_asum 1 + Pre_TAeK_asum + Treatment + age + desired_residence + $(1 \mid$ class $)$, data $=$ schools_prepost_test,REML $=$ FALSE $)$

fit8<-lmer(Post_TAeK_asum 1 + Pre_TAeK_asum + Treatment + desired_residence + $(1 \mid$ class $)$, data $=$ schools_prepost_test, $R E M L=$ FALSE $)$

anova(fit7,fit8)

summary(fit8)

fitfinaltransmission<-lmer(Post_TAeK_asum $~ 1+$ Pre_TAeK_asum + Treatment + desired_residence $+(1 \mid$ class $)$, data $=$ schools_prepost, $\mathrm{REML}=\mathrm{TRUE})$

summary(fitfinaltransmission)

anova(fitfinaltransmission)

plot(fitfinaltransmission)

plot(allEffects(fitfinaltransmission))

ranef(fitfinaltransmission) 


\section{Appendix 4. Supplementary LMM outputs}

\subsection{Pre-intervention TAeK valuation index}

Type III Analysis of Variance Table with Satterthwaite's method

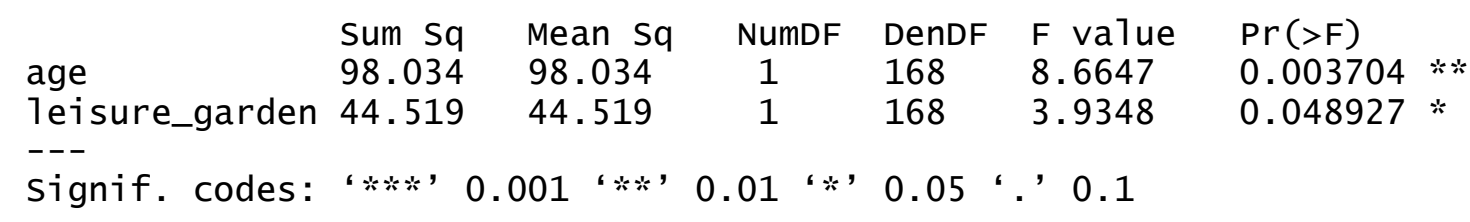

Most parsimonious linear mixed model fit by REML (Pseudo . t-tests use Satterthwaite approxi mations to degrees of freedom [lmerMod]. Formula: Pre_TAeK_Vsum $~ 1+$ age + leisure_garden + (1| class). REML criterion at convergence: 899.4. Number of obs: 171, groups: class, 15

\begin{tabular}{|c|c|c|c|c|c|}
\hline Fixed effects & Estimate & Std.Error & df & tvalue & $\operatorname{Pr}(>|t|)$ \\
\hline (Intercept) & 23.17114 & 1.10926 & $\begin{array}{l}168.0 \mathrm{e}+0 \\
2\end{array}$ & 20.89 & $<2 \mathrm{e}-16^{* * *}$ \\
\hline age & 0.14263 & 0.04723 & $\begin{array}{l}168.0 \mathrm{e}+0 \\
2\end{array}$ & 3.02 & $0.00292 * *$ \\
\hline leisure_garden_yes & 1.14675 & 0.53340 & $\begin{array}{l}168.0 \mathrm{e}+0 \\
2\end{array}$ & 2.15 & $0.03299 *$ \\
\hline \multicolumn{6}{|c|}{ 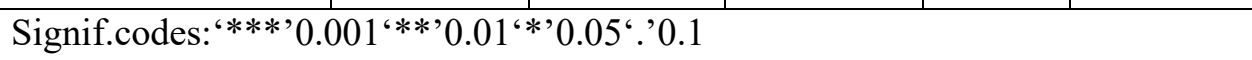 } \\
\hline
\end{tabular}

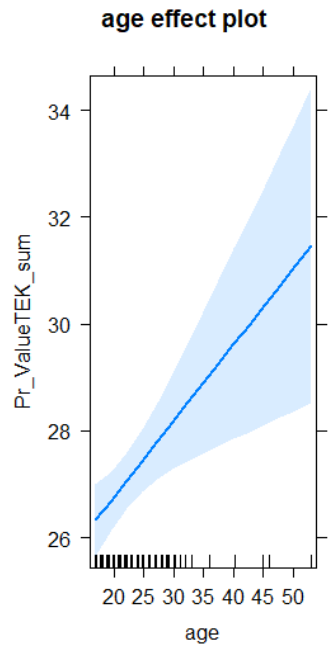

Correlation of Fixed Effects

age

leisure_garden_yes
Leisure_garden effect plot
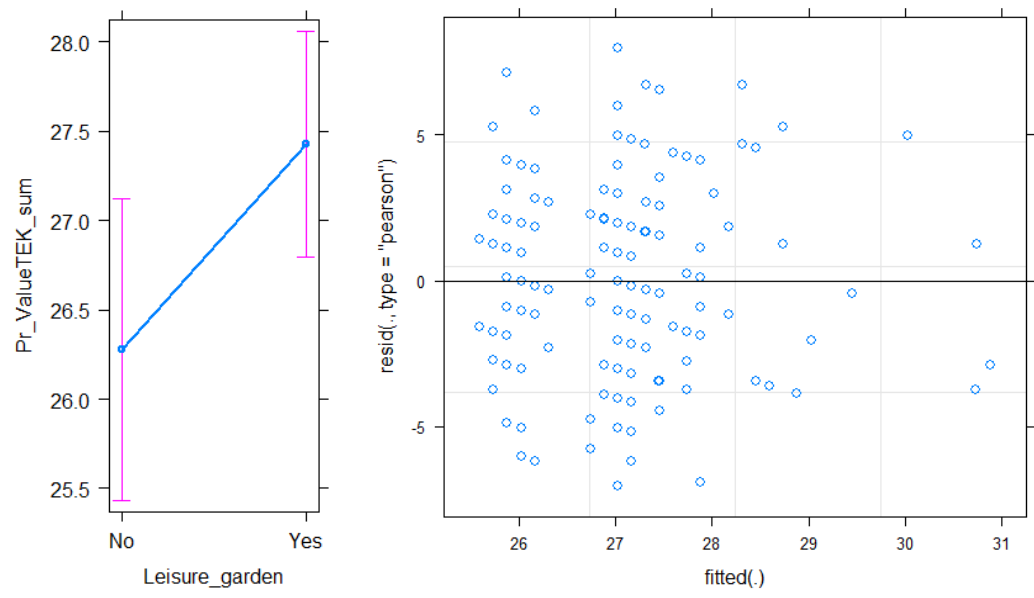

Age

$-0.923$

$-0.294$ 
Random effects:

\begin{tabular}{|l|l|l|l|}
\hline Groups & Name & Variance & Std.Dev. \\
\hline class & (Intercept) & 0.00 & 0.000 \\
\hline Residual & & 11.16 & 3.341 \\
\hline
\end{tabular}

\begin{tabular}{|l|l|}
\hline \$class & $($ Intercept $)$ \\
\hline 1 & 0 \\
\hline 2 & 0 \\
\hline 3 & 0 \\
\hline 4 & 0 \\
\hline 5 & 0 \\
\hline 6 & 0 \\
\hline 7 & 0 \\
\hline 8 & 0 \\
\hline 9 & \\
\hline
\end{tabular}

Scaled residuals:

\begin{tabular}{|l|l|l|l|l|}
\hline Min & 1Q & Median & $3 Q$ & Max \\
\hline-2.10366 & -0.67044 & 0.03481 & 0.61227 & 2.38627 \\
\hline
\end{tabular}




\subsection{Pre-intervention TAeK access index}

Type III Analysis of Variance Table with Satterthwaite's method Sum Sq Mean Sq NumDF DenDF $F$ value $\operatorname{Pr}(>F)$

program_theme

$\begin{array}{lllll}59.861 & 29.930 & 2 & 162 & 12.0204\end{array}$

desired_work

$\begin{array}{llll}29.429 & 7.357 & 4 & 162\end{array}$

12.0204

$1.357 \mathrm{e}-05 * * *$

work_rura1_nature

$23.380 \quad 23.380 \quad 1 \quad 162$

2.9547

$0.0216912 *$

Leisure_garden

$34.102 \quad 34.102 \quad 1 \quad 162$

9.3896

$0.0025568 * *$

---

Signif. codes: ‘ $* * * 0.001$ ‘**, 0.01 ‘* 0.05 ‘’ 0.1

Most parsimonious linear mixed model fit by REML. t-tests use Satterthwaite's method [lmerM odLmerTest] Formula: Pre_TAeK_a $a_{\text {sum }} \sim 1+$ program_theme + desired_work + work_rural_nat ure + leisure_garden $+(1 \mid$ class $)$. REML criterion at convergence: 638.2 . Number of obs: $171, \mathrm{~g}$ roups: class, 15

\begin{tabular}{|c|c|c|c|c|c|}
\hline Fixed effects & Estimate & Std. Error & $\mathrm{df}$ & t value & $\operatorname{Pr}(>|t|)$ \\
\hline (Intercept) & 4.6797 & 0.3650 & 162.0000 & 12.819 & $<2 \mathrm{e}-16^{* * * *}$ \\
\hline $\begin{array}{l}\text { program_theme } \\
\text { Conventional }\end{array}$ & -1.8879 & 0.3887 & 162.0000 & -4.857 & $2.79 \mathrm{e}-06^{* * *}$ \\
\hline $\begin{array}{l}\text { program_theme } \\
\text { Environmental }\end{array}$ & -0.7877 & 0.3216 & 162.0000 & -2.449 & $0.015397 *$ \\
\hline $\begin{array}{l}\text { desired_work } \\
\text { Conventional agriculture }\end{array}$ & -0.7932 & 0.3916 & 162.0000 & -2.025 & $0.044475^{*}$ \\
\hline $\begin{array}{l}\text { desired_work } \\
\text { Environmental/forestry }\end{array}$ & -0.9946 & 0.3658 & 162.0000 & -2.719 & $0.007264 * *$ \\
\hline $\begin{array}{l}\text { desired_work } \\
\text { Other }\end{array}$ & -0.9092 & 0.4121 & 162.0000 & -2.206 & $0.028776^{*}$ \\
\hline $\begin{array}{l}\text { desired_work } \\
\text { Gardening }\end{array}$ & -1.2757 & 0.4936 & 162.0000 & -2.584 & $0.010639^{*}$ \\
\hline Work_rural_natureYes & 0.7757 & 0.2532 & 162.0000 & 3.064 & $0.002557 * *$ \\
\hline Leisure_gardenYes & 0.9894 & 0.2673 & 162.0000 & 3.701 & $0.000294 * * *$ \\
\hline
\end{tabular}


module_theme effect plot

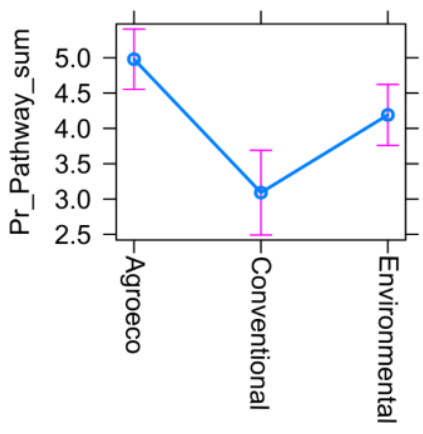

module_theme
Desired_work_sector effect plot

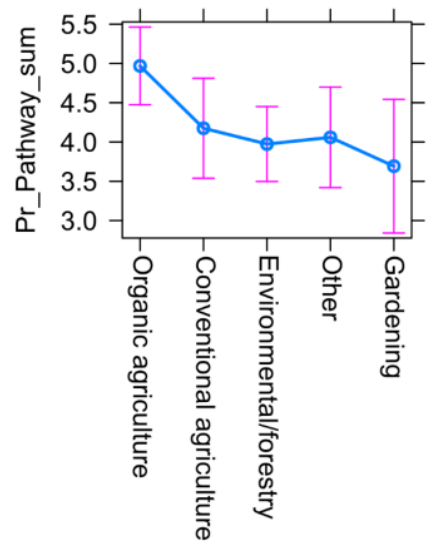

Desired_work_sector

Work_rural_nature effect plot Leisure_garden effect plot
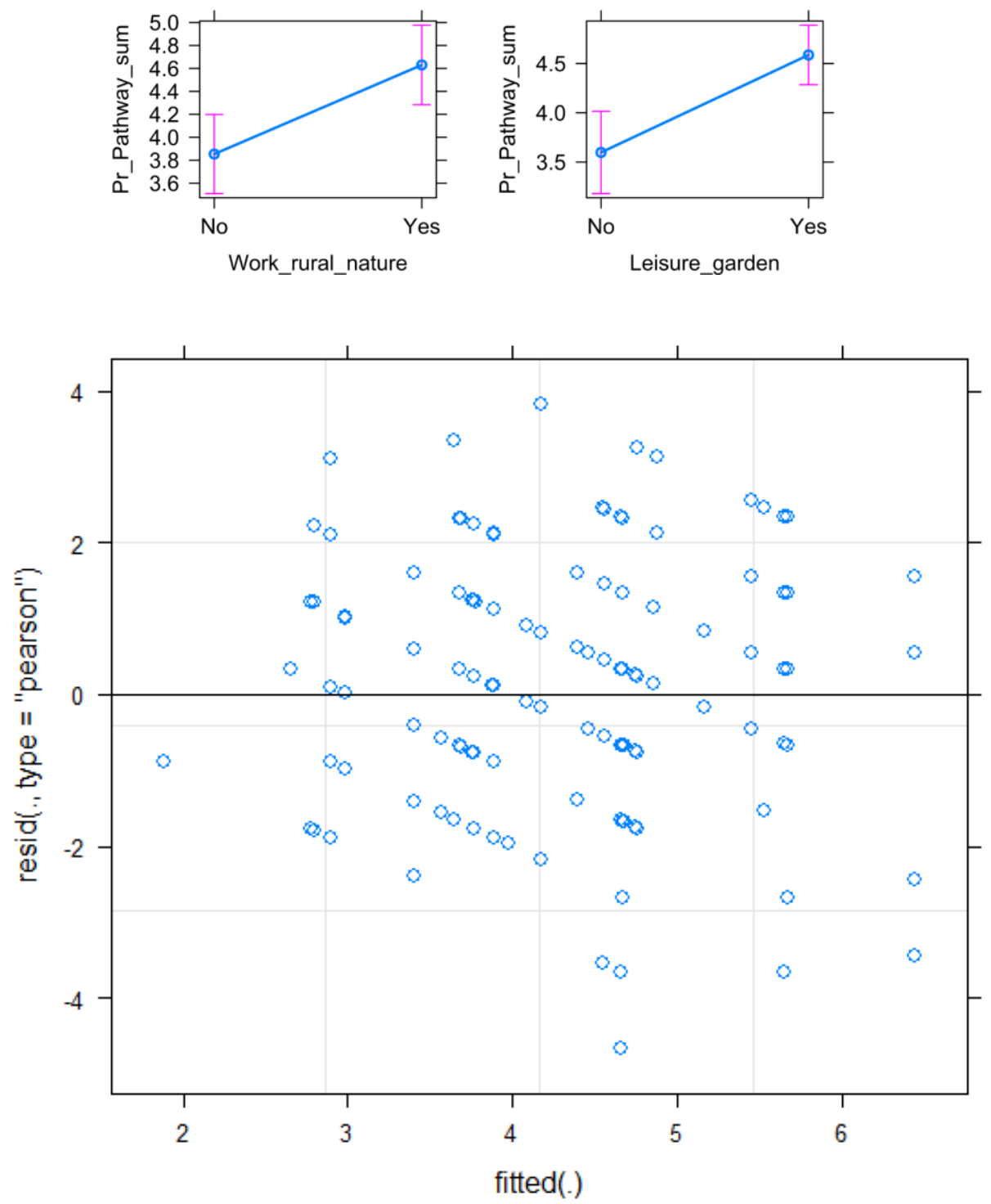


\begin{tabular}{|c|c|c|c|c|c|c|c|c|}
\hline $\begin{array}{l}\text { Correlation of } \\
\text { Fixed Effects }\end{array}$ & (Intr) & $\begin{array}{l}\text { pr_th } \\
\text { Conv }\end{array}$ & $\begin{array}{l}\text { pr_th } \\
\text { Env }\end{array}$ & $\begin{array}{l}\text { de_wo } \\
\text { Conv }\end{array}$ & $\begin{array}{l}\text { de_wo } \\
\text { En/Fo }\end{array}$ & $\begin{array}{l}\text { de_wo } \\
\text { Oth }\end{array}$ & $\begin{array}{l}\text { de_wo } \\
\text { Gard }\end{array}$ & $\begin{array}{l}\text { Work } \\
\text { yes }\end{array}$ \\
\hline $\begin{array}{l}\text { program_theme } \\
\text { Conventional }\end{array}$ & -0.414 & & & & & & & \\
\hline $\begin{array}{l}\text { program_theme } \\
\text { Environmental }\end{array}$ & -0.363 & 0.376 & & & & & & \\
\hline $\begin{array}{l}\text { desired_work } \\
\text { Conventional }\end{array}$ & -0.225 & -0.302 & -0.102 & & & & & \\
\hline $\begin{array}{l}\text { desired_work } \\
\text { Environmental/forestry }\end{array}$ & -0.481 & 0.172 & -0.332 & 0.344 & & & & \\
\hline $\begin{array}{l}\text { desired_work } \\
\text { Other }\end{array}$ & -0.442 & 0.112 & -0.086 & 0.328 & 0.477 & & & \\
\hline $\begin{array}{l}\text { desired_work } \\
\text { Gardening }\end{array}$ & -0.578 & 0.330 & 0.258 & 0.196 & 0.337 & 0.322 & & \\
\hline Work_rural_nature_yes & -0.179 & -0.199 & -0.078 & -0.025 & 0.026 & -0.058 & -0.074 & \\
\hline Leisure_garden-yes & -0.531 & 0.109 & 0.129 & -0.104 & 0.057 & 0.086 & 0.208 & -0.158 \\
\hline
\end{tabular}

Random effects:

\begin{tabular}{|l|l|l|l|}
\hline Groups & Name & Variance & Std.Dev. \\
\hline class & (Intercept) & $2.091 \mathrm{e}-16$ & $1.446 \mathrm{e}-08$ \\
\hline Residual & & $2.490 \mathrm{e}+00$ & $1.578 \mathrm{e}+00$ \\
\hline
\end{tabular}

\begin{tabular}{|l|l|}
\hline$\$$ class $^{`}$ & (Intercept) \\
\hline 111 & $8.256586 \mathrm{e}-16$ \\
\hline 121 & $-3.729046 \mathrm{e}-16$ \\
\hline 212 & $2.607870 \mathrm{e}-16$ \\
\hline 321 & $-6.253195 \mathrm{e}-19$ \\
\hline 323 & $1.776277 \mathrm{e}-16$ \\
\hline 414 & $-3.423947 \mathrm{e}-17$ \\
\hline 422 & $-1.051437 \mathrm{e}-17$ \\
\hline 513 & $-3.831467 \mathrm{e}-16$ \\
\hline 521 & $-6.771615 \mathrm{e}-16$ \\
\hline 522 & $-8.892559 \mathrm{e}-17$ \\
\hline 621 & $-5.708907 \mathrm{e}-17$ \\
\hline 622 & $4.017261 \mathrm{e}-16$ \\
\hline 722 & $1.151000 \mathrm{e}-16$ \\
\hline 812 & $-4.384147 \mathrm{e}-16$ \\
\hline 911 & $2.821219 \mathrm{e}-16$ \\
\hline
\end{tabular}

Scaled residuals:

\begin{tabular}{|l|l|l|l|l|}
\hline Min & 1Q & Median & $3 \mathrm{Q}$ & Max \\
\hline-2.9548 & -0.5636 & 0.0650 & 0.6751 & 2.4210 \\
\hline
\end{tabular}




\subsection{Post intervention TAeK valuation index}

Type III Analysis of Variance Table with Satterthwaite's method

$\begin{array}{lllllll} & \text { Sum Sq } & \text { MeanSq } & \text { NumDF } & \text { DenDF } & \text { Fvalue } & \text { Pr }(>\mathrm{F}) \\ \text { Pre_TAek_vsum } & 419.55 & 419.55 & 1 & 156.686 & 52.4136 & 1.897 \mathrm{e}-11 * * * \\ \text { treatment } & 36.15 & 18.08 & 2 & 10.105 & 2.2583 & 0.15463 \\ \text { gender_female } & 43.60 & 43.60 & 1 & 162.512 & 5.4467 & 0.02083 * \\ \text { desired_work } & 110.28 & 27.57 & 4 & 136.310 & 3.4442 & 0.01025 *\end{array}$

Signif codes: “ $* * *, 0.001$ ، $* *, 0.01$ ، $*, 0.05$ ، 0.1

Most parsimonious linear mixed model fit by REML. t-tests use Satterthwaite's method [lmerM odLmerTest] Formula: Post_TAeK_v $\mathrm{v}_{\text {sum }} \sim 1+$ Pre_TAeK_v $\mathrm{v}_{\text {sum }}+$ treatment + sex + desired_wor $\mathrm{k}+(1 \mid$ class $)$. REML criterion at convergence: 843.6. Number of obs: 172, groups: class, 15

\begin{tabular}{|c|c|c|c|c|c|}
\hline Fixed effects & Estimate & Std. Error & df & t value & $\operatorname{Pr}(>|t|)$ \\
\hline (Intercept) & 15.02391 & 1.88501 & 147.57539 & 7.970 & $3.97 \mathrm{e}-13 * * *$ \\
\hline Pre_TAeK_V $\mathrm{V}_{\text {sum }}$ & 0.44823 & 0.06416 & 157.32076 & 6.987 & $7.51 \mathrm{e}-11 * * *$ \\
\hline treatment_talk & 1.87197 & 0.87023 & 14.53101 & 2.151 & $0.04873 *$ \\
\hline treatment_talk+practical & 1.33078 & 0.79913 & 11.38433 & 1.665 & 0.12311 \\
\hline gender_female & -1.40591 & 0.61017 & 162.66098 & -2.304 & $0.02248 *$ \\
\hline $\begin{array}{l}\text { desired_work } \\
\text { conventional agriculture }\end{array}$ & -2.32367 & 0.73306 & 148.06599 & -3.170 & $0.00185^{* *}$ \\
\hline $\begin{array}{l}\text { desired_work } \\
\text { environmental/forestry }\end{array}$ & -1.74521 & 0.63195 & 105.78336 & -2.762 & $0.00678 * *$ \\
\hline $\begin{array}{l}\text { desired_work } \\
\text { other }\end{array}$ & -1.70314 & 0.74548 & 162.04090 & -2.285 & $0.02363 *$ \\
\hline $\begin{array}{l}\text { desired_work } \\
\text { gardening }\end{array}$ & -0.65308 & 0.86116 & 142.09345 & -0.758 & 0.44948 \\
\hline
\end{tabular}

Signif.codes: ${ }^{6 * * * 9} 0.0011^{6 * * 9} 0.011^{6 * 9} 0.055^{6} \cdot 0.1$ 


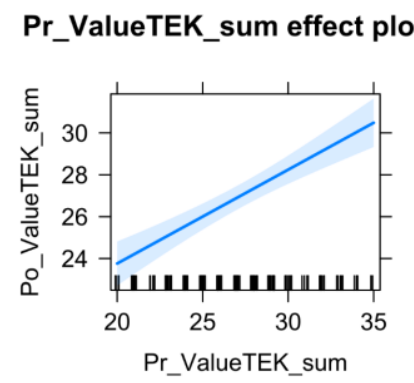

Treatment effect plot

Female effect plot

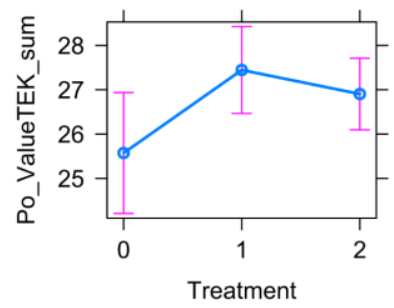

Desired_work_sector effect plot
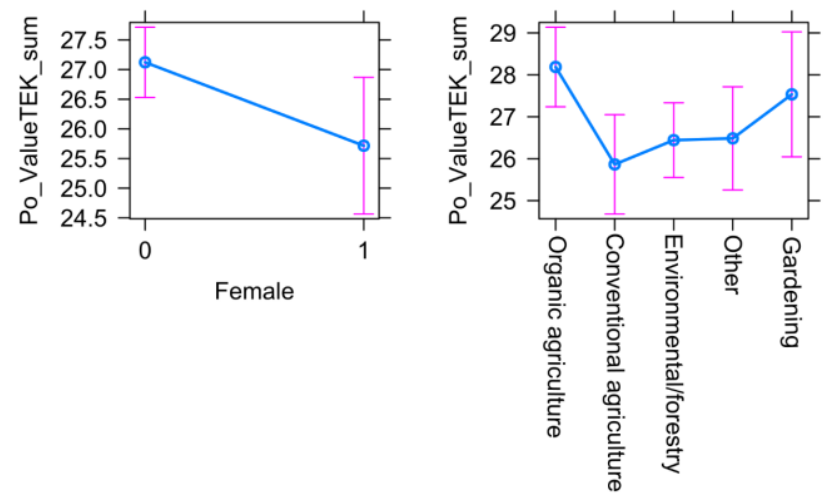

Desired_work_sector

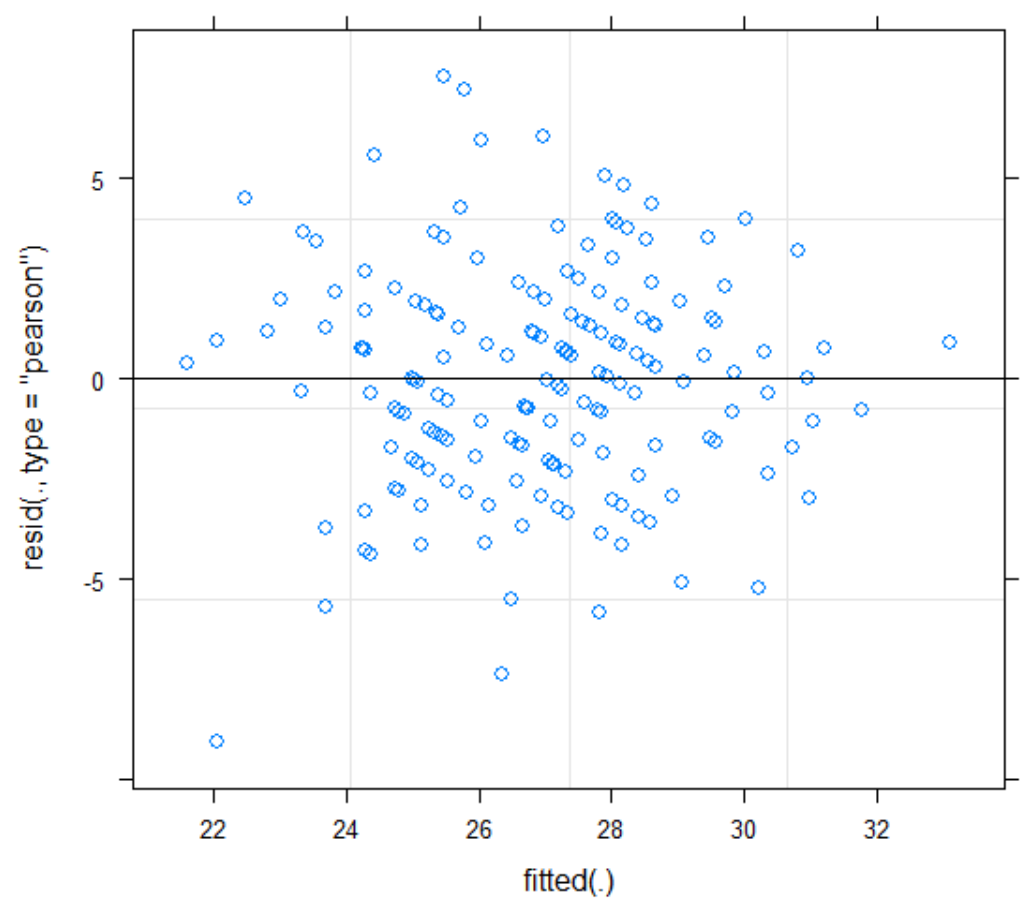




\begin{tabular}{|l|l|l|l|l|l|l|l|l|}
\hline $\begin{array}{l}\text { Correlation of } \\
\text { Fixed Effects }\end{array}$ & (Intr) & P_T_V & t_T1 & t_T2 & $\begin{array}{l}\text { gender } \\
\text { f }\end{array}$ & $\begin{array}{l}\text { de_wo } \\
\text { Conv }\end{array}$ & $\begin{array}{l}\text { de_wo } \\
\text { En/Fo }\end{array}$ & $\begin{array}{l}\text { de_wo } \\
\text { Oth }\end{array}$ \\
\hline Pre_TAeK_vsum & -0.904 & & & & & & & \\
\hline treatment_talk & -0.250 & -0.062 & & & & & & \\
\hline treatment_talk+practica & -0.270 & -0.042 & 0.701 & & & & & \\
\hline gender_female & -0.038 & -0.028 & -0.077 & -0.033 & & & & \\
\hline $\begin{array}{l}\text { desired_work } \\
\text { conventional }\end{array}$ & -0.278 & 0.082 & 0.220 & 0.073 & 0.090 & & & \\
\hline $\begin{array}{l}\text { desired_work } \\
\text { environmental/forestry }\end{array}$ & -0.178 & -0.006 & -0.005 & -0.024 & 0.190 & 0.443 & & \\
\hline $\begin{array}{l}\text { desired_work } \\
\text { other }\end{array}$ & -0.086 & -0.050 & -0.022 & -0.045 & 0.056 & 0.355 & 0.464 & \\
\hline $\begin{array}{l}\text { desired_work } \\
\text { gardening }\end{array}$ & -0.144 & 0.059 & -0.083 & -0.102 & 0.003 & 0.293 & 0.379 & 0.326 \\
\hline
\end{tabular}

Random effects:

\begin{tabular}{|c|c|c|c|}
\hline Groups & Name & Variance & Std.Dev. \\
\hline class & (Intercept) & 0.385 & 0.6205 \\
\hline Residual & & 8.162 & 2.8570 \\
\hline \$'class & & (Intercept) & \\
\hline 111 & & -0.25929371 & \\
\hline 121 & & -0.18875031 & \\
\hline 212 & & 0.06592474 & \\
\hline 321 & & -0.31691860 & \\
\hline 323 & & 0.02329777 & \\
\hline 414 & & -0.01780835 & \\
\hline 422 & & 0.53278626 & \\
\hline 513 & & 0.09213350 & \\
\hline 521 & & 0.35799334 & \\
\hline 522 & & -0.22243075 & \\
\hline 621 & & 0.22697386 & \\
\hline 622 & & -0.24330489 & \\
\hline 722 & & 0.53288689 & \\
\hline 812 & & -0.51655586 & \\
\hline 911 & & -0.06693389 & \\
\hline
\end{tabular}

Scaled residuals:

\begin{tabular}{|l|l|l|l|l|}
\hline Min & 1Q & Median & $3 \mathrm{Q}$ & Max \\
\hline-3.1658 & -0.6160 & 0.0174 & 0.5666 & 2.6372 \\
\hline
\end{tabular}


Type III Analysis of Variance Table with Satterthwaite's method

$\begin{array}{lllllll} & \text { Sum Sq } & \text { Mean Sq } & \text { NumDF } & \text { DenDF } & \text { F value } & \operatorname{Pr}(>F) \\ \text { Pre_TAeK_asum } & 102.516 & 102.516 & 1 & 167 & 60.5018 & 7.233 \mathrm{e}-13 \\ * * * & 14.404 & 7.202 & 2 & 167 & 4.2503 & 0.015832 * \\ \text { treatment } & 13.922 & 13.922 & 1 & 167 & 8.2162 & 0.004687 * \\ \text { desired_residence } & & & & & & \end{array}$

Signif. codes: “***’ 0.001 “**’ 0.01 ‘* 0.05 ‘’ 0.1

Most parsimonious linear mixed model fit by REML. t-tests use Satterthwaite's method ['ImerM odLmerTest'] Formula: Post_TAeK_a $\mathrm{a}_{\text {sum }} \sim 1+$ Pre_TAeK_a $\mathrm{a}_{\text {sum }}+$ Treatment + desired_residence $+(1 \mid$ class $)$. REML criterion at convergence: 583.6. Number of obs: 172, groups: class, 15

\begin{tabular}{|c|c|c|c|c|c|}
\hline Fixed effects & Estimate & Std. Error & $\mathrm{df}$ & $\mathrm{t}$ value & $\operatorname{Pr}(>|t|)$ \\
\hline (Intercept) & 1.39638 & 0.36485 & 167.00000 & 3.827 & $0.000183 * * *$ \\
\hline Pre_TAeK_a $a_{\text {sum }}$ & 0.43624 & 0.05608 & 167.00000 & 7.778 & $7.23 \mathrm{e}-13 * * *$ \\
\hline treatment_talk & 0.75799 & 0.31202 & 167.00000 & 2.429 & $0.016187 *$ \\
\hline treatment_talk+practical & 0.84278 & 0.29317 & 167.00000 & 2.875 & $0.004571 * *$ \\
\hline desired_residence_yes & 0.65787 & 0.22951 & 167.00000 & 2.866 & $0.004687 * *$ \\
\hline
\end{tabular}



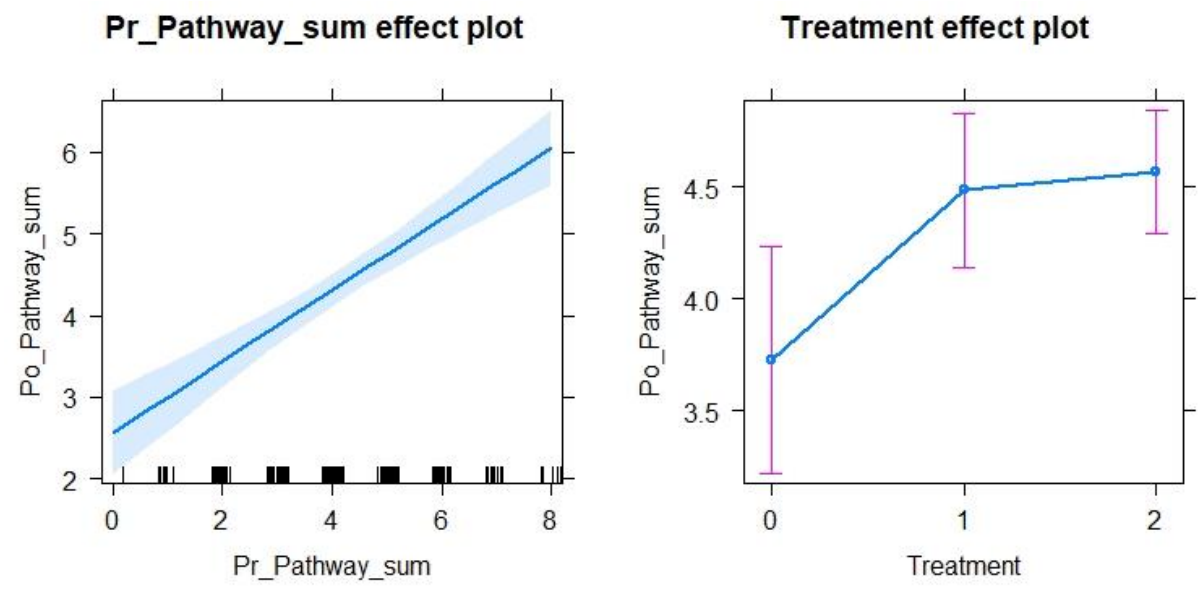

\section{future_residence_rural effect plot}
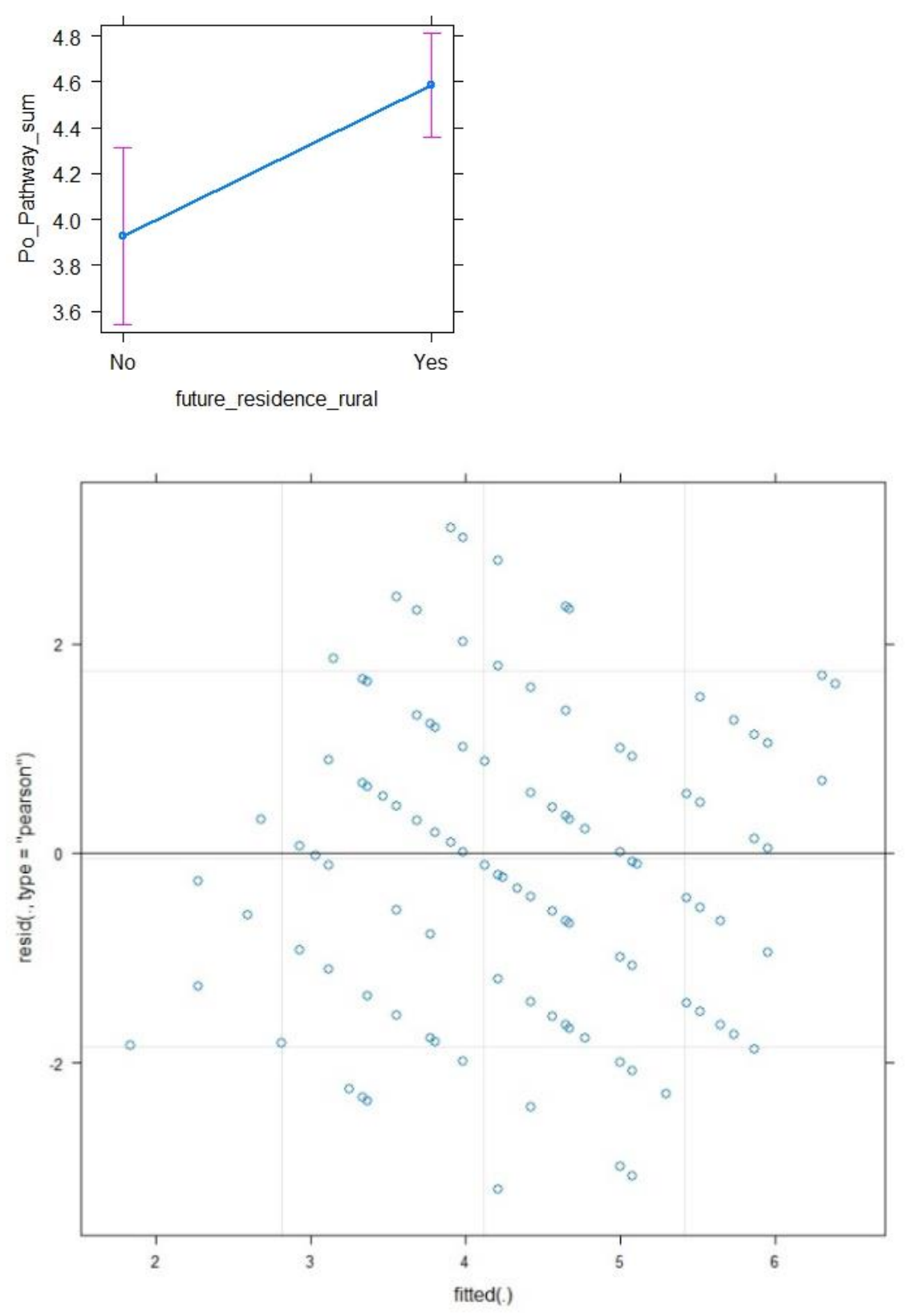


\begin{tabular}{|l|l|l|l|l|}
\hline Correlation of Fixed Effects & (Intr) & Pre_TAeK_Asum & treatment_T1 & \\
\hline Pre_TAeK_a & -0.506 & & & \\
\hline treatment_talk & -0.490 & -0.174 & & \\
\hline treatment_talk+practical & -0.613 & -0.090 & 0.729 & \\
\hline desired_residence_yes & -0.439 & -0.121 & 0.032 & 0.108 \\
\hline
\end{tabular}

Random effects:

\begin{tabular}{|l|l|l|l|}
\hline Groups & Name & Variance & Std.Dev. \\
\hline class & (Intercept) & 0.000 & 0.000 \\
\hline Residual & & 1.694 & 1.302 \\
\hline
\end{tabular}

\begin{tabular}{|l|l|}
\hline$\$$ `lass $^{\prime}$ & (Intercept) \\
\hline 111 & 0 \\
\hline 121 & 0 \\
\hline 212 & 0 \\
\hline 321 & 0 \\
\hline 323 & 0 \\
\hline 414 & 0 \\
\hline 422 & 0 \\
\hline 513 & 0 \\
\hline 521 & 0 \\
\hline 522 & 0 \\
\hline 621 & 0 \\
\hline 622 & 0 \\
\hline 722 & 0 \\
\hline 812 & 0 \\
\hline 911 & 0 \\
\hline
\end{tabular}

Scaled residuals:

\begin{tabular}{|l|l|l|l|l|}
\hline Min & 1Q & Median & $3 \mathrm{Q}$ & Max \\
\hline-2.46273 & -0.62135 & -0.02063 & 0.70814 & 2.38201 \\
\hline
\end{tabular}

